Article

\title{
Dewatering of Mine Tailings Slurries Using Superabsorbent Polymers (SAPs) Reclaimed from Industrial Reject of Baby Diapers: A Preliminary Study ${ }^{\dagger}$
}

\author{
Amal Sahi, Khadija El Mahboub, Tikou Belem *(D), Abdelkabir Maqsoud and Mamert Mbonimpa \\ Research Institute of Mines and Environment, Université du Québec en Abitibi-Témiscamingue (UQAT), \\ 445 Boul. de l’Université, Rouyn-Noranda, QC J9X 5E4, Canada; Amal.Sahi@uqat.ca (A.S.); \\ Khadija.Elmahboub@uqat.ca (K.E.M.); Abdelkabir.Maqsoud@uqat.ca (A.M.); \\ Mamert.Mbonimpa@uqat.ca (M.M.) \\ * Correspondence: Tikou.Belem@uqat.ca; Tel.: +1-819-762-0971 (ext. 2359) \\ + Some of the results in this article had been presented at the 70th Canadian Geotechnical Conference, \\ GeoOttawa, Canada.
}

Received: 27 October 2019; Accepted: 9 December 2019; Published: 13 December 2019

\begin{abstract}
Traditional deposition of tailings slurry in a tailings storage facility (TSF) can create risks of dike failure. In order to minimize these risks and slurry spillage, the surface deposition technique of densified tailings (DT) through dewatering of the slurry has emerged. The DT technique has the potential to maximize water reuse, improve the shear strength of surface tailings, and reduce the ecological footprint of TSF. The consistency of DT covers a continuum ranging from thickened state, to paste state, to dry state. Despite its efficiency and economic feasibility, DT densification using thickeners sometimes proves unable to achieve the design target solids mass concentration $\left(C_{\mathrm{w} \%}\right)$. Hence, the use of superabsorbent polymers (SAPs) seems to represent a promising alternative, owing to their higher water absorbent capacity. In this paper, superabsorbent polymers (SAPs) reclaimed from industrial reject of baby diapers (Na-polyacrylates) are explored as a promising alternative to mine tailings slurries dewatering. To this end, laboratory-scale dewatering tests have been performed using two grades of Na-polyacrylate SAPs (grade 1 SAP = SAG-A06P coarse-grained, and grade $2=$ SAG-M01P-100 medium-grained) for the tailings slurries densification. A higher water absorbency (or swelling capacity) was observed using the coarser SAPs (SAG-A06P) compared to the finer SAPs (SAG-M01P-100). The preliminary results showed that a SAP volume dosage in the range 10-13 kg of $\mathrm{SAP} / \mathrm{m}^{3}$ of slurry allowed achieving a final solids mass concentration $\left(C_{\mathrm{w} \% \text { _final }}\right) \geq 70 \%$, despite the occurrence of gel-blocking phenomenon.
\end{abstract}

Keywords: tailings storage facility (TSF); tailings slurry; tailings dewatering; superabsorbent polymers; industrial reject baby diapers; thickened tailings; paste tailings; filtered tailings

\section{Introduction}

Mining activity generates large amounts of solids wastes such as waste rocks and tailings. Waste rocks are stored in waste rocks pile while mine tailings are commonly stored as slurry in tailings storage facilities (TSF), surrounded by embankment dams [1]. Traditional deposition in TSF can create risks of dike failure [2-7] due to slope instability following excessive stress in the foundation soil, excessive stress in the embankment dam, and inadequate control of water pressure leading to liquefaction (static or dynamic) [8]. In order to minimize the risks of dike failure and slurry spillage, the surface deposition technique of densified tailings has emerged, even if thickening requires a huge dewatering capacity of 
the slurry. The thickened tailings technology has the potential to maximize water reuse, improve the shear strength of surface tailings, and reduce the ecological footprint of TSF by taking up a smaller area and volume $[9,10]$. The consistency of dewatered-or densified-tailings covers a continuum ranging from slurry state to thickened state (like molasses), to paste state (like toothpaste), and finally to dry state (like soil) [11]. In the mining industry, this consistency is usually defined according to the pulp mass density or the solids mass concentration $\left(C_{\mathrm{w} \%}=100 \times M_{\text {dry-tailings }} / M_{\text {slurry }}\right)$. Thus, the thickened tailings would have a final $C_{\mathrm{w} \%}$ of between $45 \%$ and $70 \%$, the paste tailings with a final $C_{\mathrm{w} \%}$ of between $70 \%$ and $85 \%$, and the dehydrated tailings with a final $C_{\mathrm{w} \%}$ of greater than $85 \%[11,12]$.

When the operation is underground, an alternative or supplement to the surface storage would be returning to the voids created up to $50 \%$ of the tailings in the form of cemented paste backfill $[1,10,13-15]$. When sulphide minerals in mine waste stored in surface are exposed to air and in the presence of water and their acid neutralization potential is not sufficient, or has been exhausted [1], these waste can produce acid mine drainage (AMD). Due to the stringent environmental regulations, these large amounts of wastes must be managed adequately. More often than not, the mining industry is forced to constantly improve their waste management practices. Indeed, densified tailings offered a good response to large tailings impoundments problems by reducing the volume of waste and eventually allowing the risk prevention of tailings dam failure [16,17]. Figure 1 outlines the conventional management of fine tailings by the mining industry.

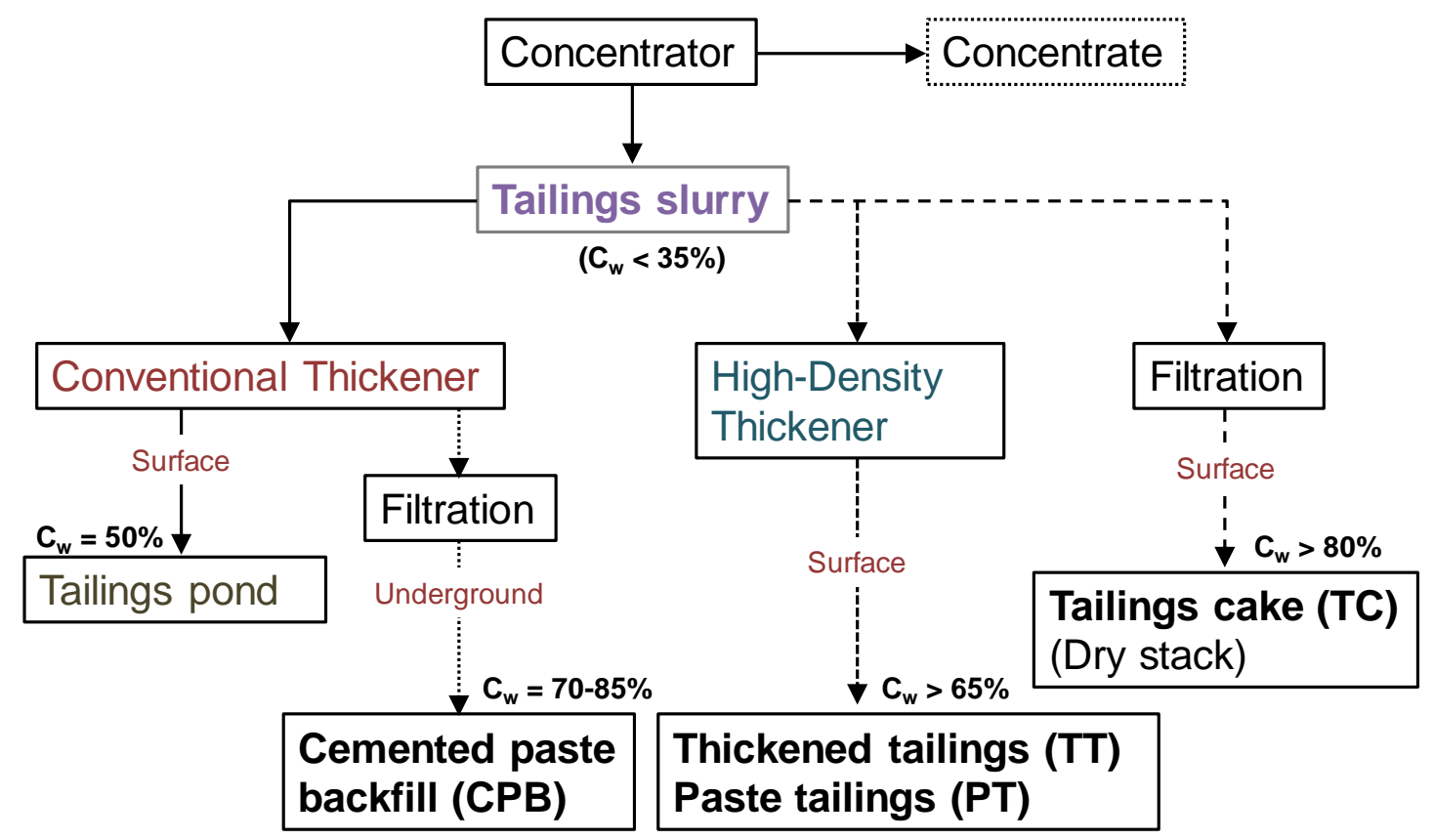

Figure 1. General scheme of conventional methods of the tailings management.

Accordingly, dewatering/densifying techniques aimed at increasing the tailings solids mass concentration. Various conventional techniques exist such as hydrocyclones, high-rate, high-density, and deep cone thickeners. Despite their efficiency and economic feasibility, these techniques prove sometimes unable to achieve the targeted design solids mass concentration (i.e., low water content). Hence, the use of superabsorbent polymers (SAPs) could represent a promising alternative, owing to their higher capacity of water absorption. SAPs are salt polyacrylates (e.g., sodium or Na), capable of absorbing and retaining from 100 to 1000 times their mass in deionized water [18]. The SAPs are commonly in the form of hydrophilic polymer chains that can absorb and retain aqueous fluids through swelling process [18-21]. Figure 2 presents the SAP in dry and swollen states and its molecular interactions (case of Na-polyacrylate). 

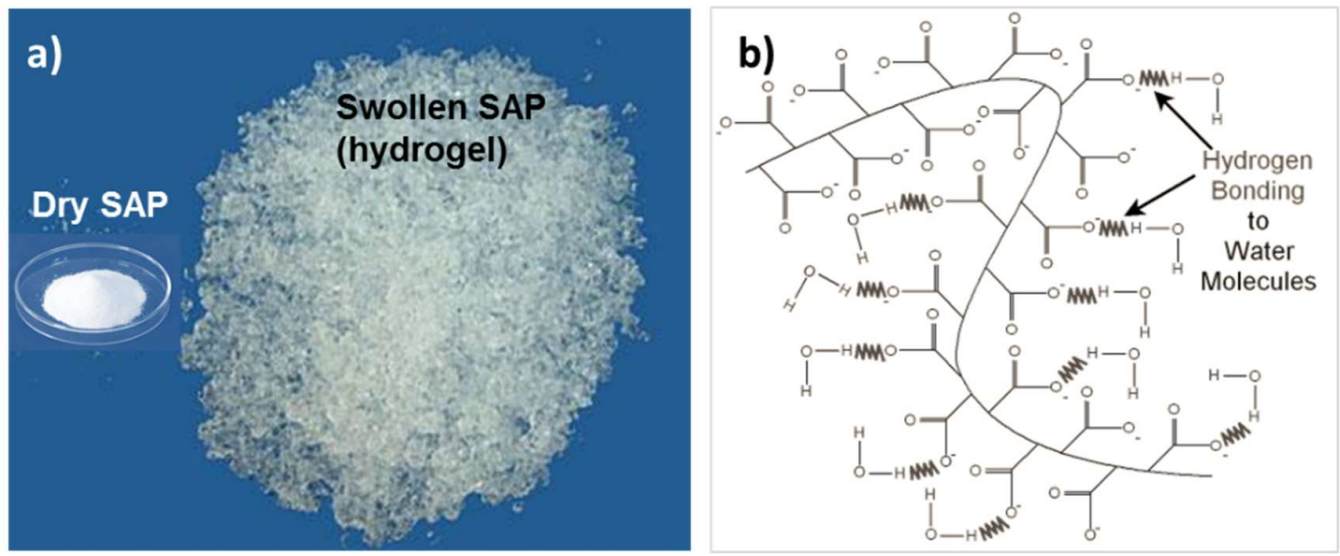

Figure 2. Superabsorbent polymer (SAP): (a) dry and swollen SAP (hydrogel), (b) molecular interactions of Na-polyacrylate.

Superabsorbent polymers are widely used in many fields, such as hygienic products, horticulture, gel actuators, drug-delivery systems, and coal dewatering [22]. Recently, SAPs have been used for dewatering and densifying oil sands mature fine tailings [23-25]. Besides, their absorption capacity will depend on various physico-chemical parameters such as temperature, $\mathrm{pH}$ of the slurry, composition and concentration of the chemical elements in the tailings slurry, presence of salts and/or cations, etc. [18,26-28].

The main objective of this paper is to assess the potential use of superabsorbent polymers (SAPs) for mine tailings slurry dewatering and to obtain densified tailings for surface storage. To do so, the aim is to eliminate all the conventional dewatering systems by replacing them with SAPs (as shown in Figure 3). This objective should be reached through the assessment of the SAP mine water absorbent capacity and its dosage optimization to allow reaching a solids mass concentration set at $68 \%$ that is targeted by Mine $\mathrm{A}\left(\mathrm{C}_{\mathrm{w} \% \text {-target }}\right)$. In this preliminary study, instead of using commercially purchased polymers, SAPs reclaimed from industrial reject of baby diapers by a recycling company Recyc PHP inc. (Quebec, QC, Canada) were used.
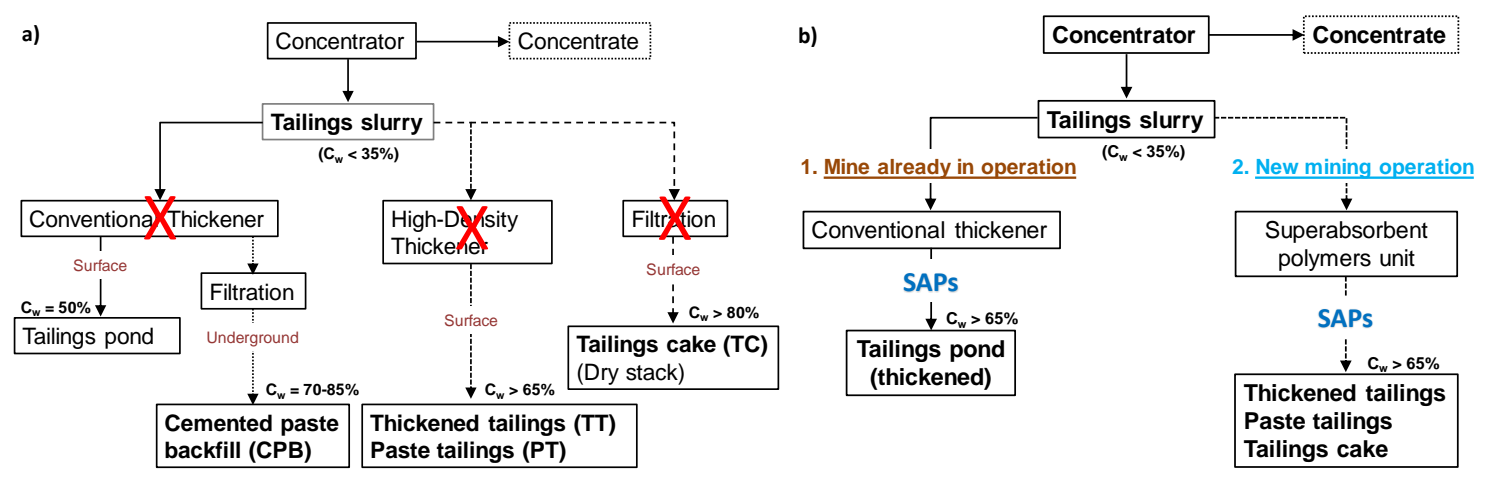

Figure 3. The use of SAPs to obtain densified tailings: (a) eliminating all conventional dewatering systems, (b) replacing all conventional dewatering system with SAPs, either for a mine already in operations or for new mine operations.

For a mine already in operation (Figure 3b, case 1), it would be possible to obtain thickened tailings at the deposit point of the storage area by adding progressively the SAPs using, for example, a particle projection gun (case of a single use of SAPs). On the other hand, in the event that the recycling of the water absorbed by the SAPs is required, the use of geotextile or other textile bags would be recommended in order to recover the swollen SAPs and recycling them by the most appropriate desorption technique. 
In the case of a new mine (Figure 3b, case 2), SAPs can be added directly to the tailings slurry to obtain densified tailings (i.e., thickened and paste tailings or tailings cake) or to produce cemented paste backfill.

\section{Materials and Methods}

\subsection{Materials}

\subsubsection{Tailings Sample and Slurry Supernatant Water}

The tailings slurry used in this study was sampled from Mine A located in Abitibi area (Quebec, Canada). This sample was collected from the ore processing plant, and was stored in plastic barrels. After transferring to the lab, the slurry was first homogenized, and of which a representative quantity was sampled for different characterizations. Physical and mineralogical characterizations were performed. The grain size distribution of the tailings was determined using a Malvern ${ }^{\circledR}$ Mastersizer S2000 Laser particle size analyzer (Malvern, United Kingdom). The tailings mineralogy was determined by X-Ray diffraction using the D8 Advance model of Burker A.X.S (Madison, WI, USA). The relative density of the tailings $\left(D_{R}\right.$ or $G_{s}$ ) was determined to be 2.7, using the helium pycnometer AccuPyc 1330 from Micrometrics ${ }^{\circledR}$ (Norcross, GA, USA).

The tailings grain size distribution (GSD) is presented in Figure 4, while the tailings gradation parameters determined from the GSD in Figure 4 and the mineralogical properties are listed in Table 1. It should be mentioned that the as-received slurry solids mass concentration $\left(C_{\mathrm{w}}\right)$ was $50 \%$.
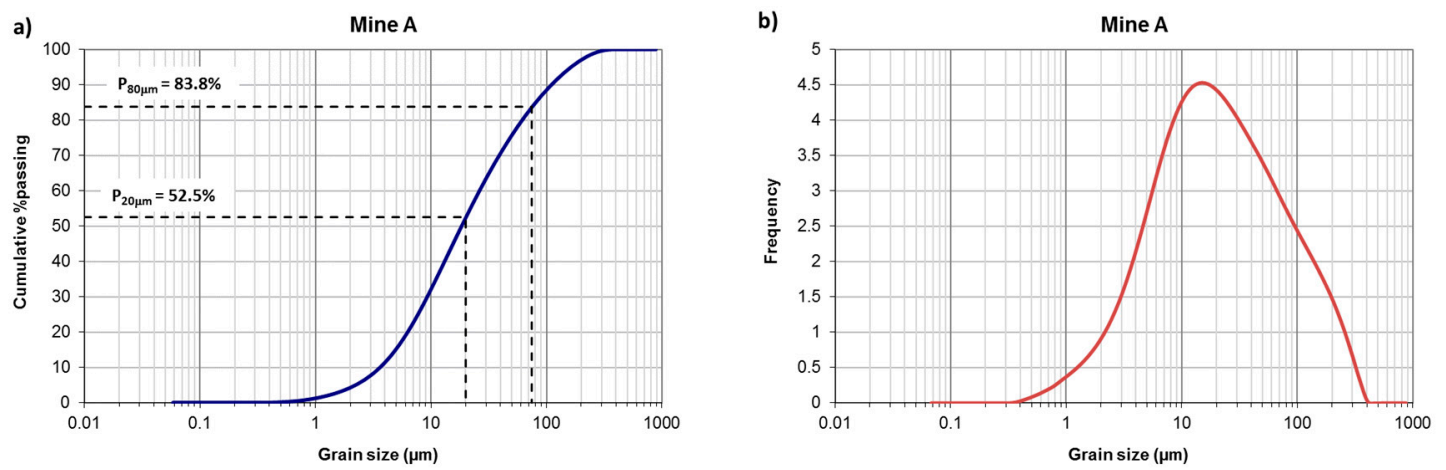

Figure 4. Grain size distribution curves of the tailings sample (Mine A): (a) cumulative distribution; (b) incremental distribution.

Table 1. Physical and mineralogical properties of tailings sample from Mine A.

\begin{tabular}{cccc}
\hline Parameter & Value & Mineral & Grade (\%) \\
\hline $\mathrm{D}_{10}$ & $3.2 \mu \mathrm{m}$ & Quartz & 28.14 \\
$\mathrm{D}_{30}$ & $9.8 \mu \mathrm{m}$ & Chlorite & 4.3 \\
$\mathrm{D}_{50}$ & $21.7 \mu \mathrm{m}$ & Albite & 30 \\
$\mathrm{D}_{60}$ & $31.6 \mu \mathrm{m}$ & Oligoclase & 4.8 \\
$\mathrm{D}_{90}$ & $112.1 \mu \mathrm{m}$ & Labradorite & 6.2 \\
$\mathrm{C}_{\mathrm{U}}$ & 9.8 & Orthoclase & 14 \\
$\mathrm{C}_{\mathrm{c}}$ & 0.9 & Biotite & 6.4 \\
$\mathrm{P}_{20} \mu \mathrm{m}$ & $52.5 \%$ & Calcite & 3.2 \\
$\mathrm{P}_{80 \mu \mathrm{m}}$ & $83.8 \%$ & Pyrite & 1.62 \\
\hline
\end{tabular}

Table 1 shows that the values of $\mathrm{D}_{10}$ and $\mathrm{D}_{60}$ (diameter corresponding respectively to $10 \%$ and $60 \%$ passing on the cumulative grain-size distribution) correspond respectively to 3.2 and $31.6 \mu \mathrm{m}$. These values are typical of hard rock mine tailings [1]. The results of the mineralogical analysis presented in the same table (the two columns on the right) show that the tailings are composed mainly by silicates 
(quartz, chlorite, albite, oligoclase, labradorite, orthoclase, and biotite) that correspond to $93.8 \%$ of total mineralogy; carbonate and sulfide represent $3 \%$ and $1.6 \%$ of total mineralogy, respectively.

Mine A water used in this study was the supernatant (or bleeding water) collected from the top of the slurry barrels after the tailings settlement. The absorbency tests were performed in order to determine the capacity of the SAPs to absorb this mine water.

\subsubsection{Superabsorbent Polymers (SAPs) Reclaimed from Industrial Reject of Baby Diapers}

Two grades of Na-polyacrylate SAPs from our partner and supplier, Recyc PHP Inc., were tested in this study with the aim at evaluating their water absorbent capacity (or degree of swelling) in mine water: larger size particles grade 1 SAP, SAG-A06P and medium size particles grade 2 SAP, SAG-M01P-100 (see Table 2).

Table 2. Particle gradation of the two Na-polyacrylate SAP grades (SAG-A06P and SAG-M01P-100).

\begin{tabular}{ccc}
\hline Particle Gradation & $\begin{array}{c}\text { Grade 1 SAP = Grade SAG-A06P } \\
\text { (Larger Size Particles) }\end{array}$ & $\begin{array}{c}\text { Grade 2 SAP = Grade } \\
\text { SAG-M01P-100 (Medium Size } \\
\text { Particles) }\end{array}$ \\
\hline $1200 \mu \mathrm{m}$ & $0 \%$ & $0 \%$ \\
between 600 and $1200 \mu \mathrm{m}$ & $4 \%$ & $\approx 1 \%$ \\
between 300 and $600 \mu \mathrm{m}$ & $91 \%$ & $78 \%$ \\
between 150 and $300 \mu \mathrm{m}$ & $\approx 5 \%$ & $20 \%$ \\
between 75 and $150 \mu \mathrm{m}$ & trace & $\approx 1 \%$ \\
$<75 \mu \mathrm{m}$ & $0 \%$ & trace \\
\hline
\end{tabular}

\subsection{Methods}

The methodology adopted consists in preliminary optimization of the SAP dosages to be used for the tailings slurry dewatering tests in relation with the residence time. It should be mentioned that the goal is to achieve a final solids mass concentration $\left(C_{w \% \_f i n a l}\right)$ varying between $68 \%$ and $90 \%$. Laboratory experiments were carried out in two stages: (i) supernatant mine water absorption tests by adding the SAP to water (direct addition mode), and (ii) the tailings slurry dewatering tests by soaking the SAP contained in geotextile bags (indirect addition mode). Figure 5 illustrates the three steps inherent to the indirect addition mode using a geotextile bag containing dry SAPs [29].

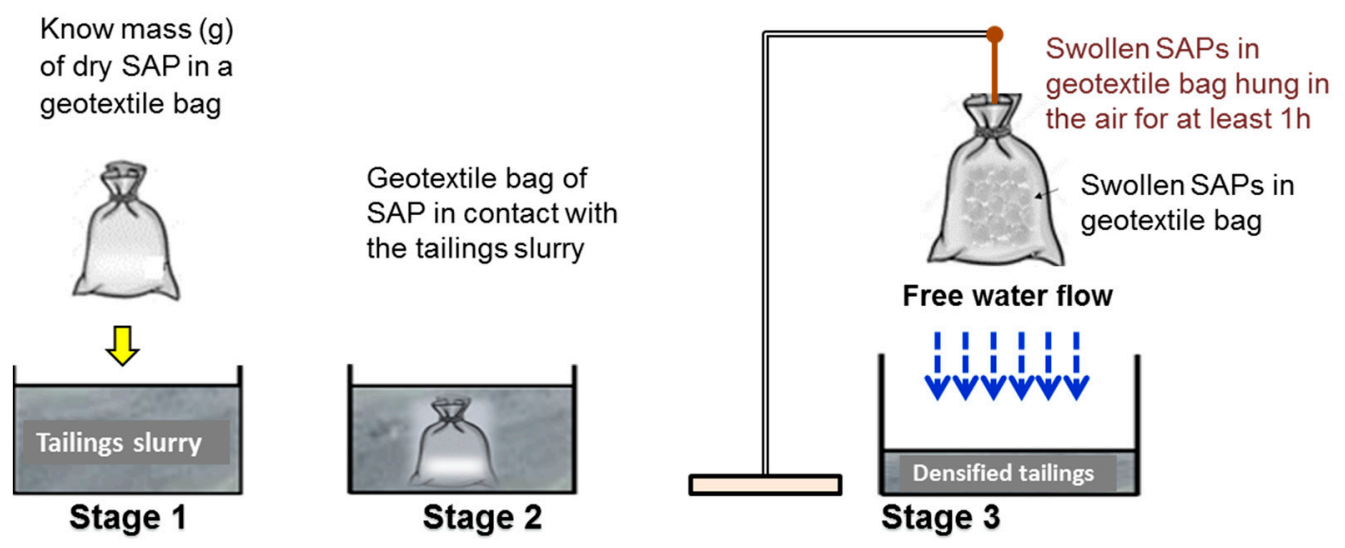

Figure 5. Diagram illustrating the three steps leading to the absorption test using dry SAPs in a geotextile bag by the indirect addition mode (contact with the slurry).

\subsubsection{SAP Dosages Calculation and Expression for the Absorbency Parameters}

The SAPs dosages can be done either by mass dosage ( $\left.D_{\mathrm{mSAP}}\right)$, or by volume dosage $\left(D_{\mathrm{vSAP}}\right)$. These dosages can be achieved either in relation to the slurry or in relation to the water alone/contained in the slurry. The mass dosage of the SAP can be defined as the ratio of the dry mass of any type and 
grade of SAP $\left(M_{\text {dry-SAP }}\right)$ to the mass of the slurry $\left(M_{\text {slurry }}\right)$ or of the initial water (free or contained in the slurry) $\left(M_{\text {water }}\right)$ as follows [29]:

$$
\begin{aligned}
& D_{m S A P-s}=\frac{M_{\text {dry-SAP }}}{M_{\text {slurry }}}, \\
& D_{m S A P-w}=\frac{M_{\text {dry-SAP }}}{M_{\text {water }}},
\end{aligned}
$$

The volume dosage of the SAP can be defined as the ratio of the dry mass of any type and grade of SAP ( $\left.M_{\text {dry-SAP }}\right)$ to the volume of the slurry $\left(V_{\text {slurry }}\right)$ or of the initial water (free or contained in the slurry) $\left(M_{\text {water }}\right)$ as follows [29]:

$$
\begin{aligned}
& D_{v S A P-s}=\frac{M_{\text {dry-SAP }}}{V_{\text {slurry }}}=\rho_{\text {slurry }}\left(\frac{M_{\text {dry } y \text { SAP }}}{M_{\text {slurry }}}\right)=\rho_{\text {slurry }} \times D_{m S A P-s,} \\
& D_{\text {vSAP-w }}=\frac{M_{\text {dry-SAP }}}{V_{\text {water }}}=\rho_{\text {water }}\left(\frac{M_{\text {dry }-S A P}}{M_{\text {water }}}\right)=\rho_{\text {water }} \times D_{m S A P-w},
\end{aligned}
$$

where $\rho_{\text {slurry }}$ is the slurry density (in $\mathrm{g} / \mathrm{cm}^{3}, \mathrm{~kg} / \mathrm{m}^{3}$, or $\mathrm{t} / \mathrm{m}^{3}$ ). The water density $\rho_{\text {water }}$ (or $\rho_{\mathrm{w}}$ ) is $1 \mathrm{~g} / \mathrm{cm}^{3}$ (or $1000 \mathrm{~kg} / \mathrm{m}^{3}$, or $1 \mathrm{t} / \mathrm{m}^{3}$ ) and the tailings slurry density is calculated as follows:

$$
\rho_{\text {slurry }}=\left(\frac{C_{w}}{\rho_{s-\text { tailings }}}+\frac{1-C_{w}}{\rho_{w}}\right)^{-1},
$$

where $\rho_{\text {s-tailings }}$ is the tailing grains density (in $\mathrm{g} / \mathrm{cm}^{3}, \mathrm{~kg} / \mathrm{m}^{3}$, or $\mathrm{t} / \mathrm{m}^{3}$ ). The possible dosage units are as follows:

- $D_{m S A P}$ : in $\mathrm{kg}$ of $\mathrm{SAP} /$ ton of slurry/water (is equivalent to $\mathrm{g} / \mathrm{kg}$ ), or in $\mathrm{g}$ of $\mathrm{SAP} / \mathrm{g}$ of slurry/water (or in $\mathrm{kg} / \mathrm{kg}$, ton/ton).

- $\quad D_{v S A P}:$ in $\mathrm{kg}$ of $\mathrm{SAP} / \mathrm{m}^{3}$ of slurry/water (is equivalent to $\mathrm{g} / \mathrm{L}$ ), or in ton of $\mathrm{SAP} / \mathrm{m}^{3}$ of slurry/water (is equivalent to $\mathrm{g} / \mathrm{mL}$ ). In the following, only the units in $\mathrm{kg} / \mathrm{m}^{3}$ for $D_{\mathrm{vSAP}}$ are used for the presentation of the obtained results.

In order to quantify the SAPs absorbency, three main parameters can be calculated [29]:

The percentage of absorbed water, $\mathrm{W}_{\mathrm{SAP}}(\%)$

$$
W_{S A P}(\%)=\frac{M_{\text {absorbed-water }}}{M_{\text {initial-water }}} \times 100=\frac{M_{\text {swollen-SAP }}-M_{\text {dry }-S A P}}{M_{\text {initial-water }}} \times 100,
$$

The absorbency ratio, $\mathrm{K}_{\mathrm{SAP}}$, i.e., the number of times the mass of the SAP

$$
K_{S A P}=\frac{M_{\text {swollen }-S A P}}{M_{d r y}-S A P},
$$

The degree of swelling, swelling ratio or swelling capacity, Q (e.g., [18])

$$
Q=\frac{M_{\text {swollen-SAP }}-M_{d r y-S A P}}{M_{d r y-S A P}}=\frac{M_{a b s o r b e d-w a t e r}}{M_{d r y-S A P}}=\left(K_{S A P}-1\right)=\frac{M_{\text {initial-water }} \times W_{S A P}(\%)}{100 \times M_{d r y-S A P}},
$$

Figure 6 presents the results of deionized water absorbency tests using the two grades of SAP used in this study: grade 1 SAP, named SAG-A06P (large size particles), and grade 2 SAP, named SAG-M01P-100 (medium size particles, which is finer than SAG-A06P). Figure 6a shows the absorption kinetics of both grades of SAP where $100 \mathrm{mg}$ of SAP is added directly to $200 \mathrm{~mL}$ of deionized water. It can be observed that after $1 \mathrm{~h}$ of contact between SAP and deionized water, the equilibrium of their swelling is reached. This is called the equilibrium degree of swelling (or equilibrium absorbency), $Q_{\text {eq. }}$. 
It can also be observed that the $Q_{\text {eq }}$ is higher with grade 1 SAP (224 mL/g) than with grade 2 SAP (151 $\mathrm{mL} / \mathrm{g})$. Grade 1 has a water absorbent capacity 1.5 times greater than that of grade 2 . According to the work done by [28], this could be due directly to the gradation of the polymer particles. Buffer solutions with $\mathrm{pH}$ in the range 1-13 were used to assess the $\mathrm{pH}$ sensitivity of SAP hydrogels. The desired acidic and basic $\mathrm{pHs}$ were adjusted by hydrochloric acid $(\mathrm{HCl})$ and sodium hydroxide $(\mathrm{NaOH})$ solutions, respectively. The $\mathrm{pH}$ values were precisely checked using a Fisher Scientific accumet ${ }^{\circledR}$ XL Meter Series $\mathrm{pH}$-meter. The $\mathrm{pH}$ dependence of equilibrium degree of swelling $Q_{\text {eq }}$ is shown in Figure $6 \mathrm{~b}$ where 80 $\mathrm{mg}$ of SAP is added directly to $200 \mathrm{~mL}$ of deionized water, and which confirms the results seen in the literature (e.g., [18]).
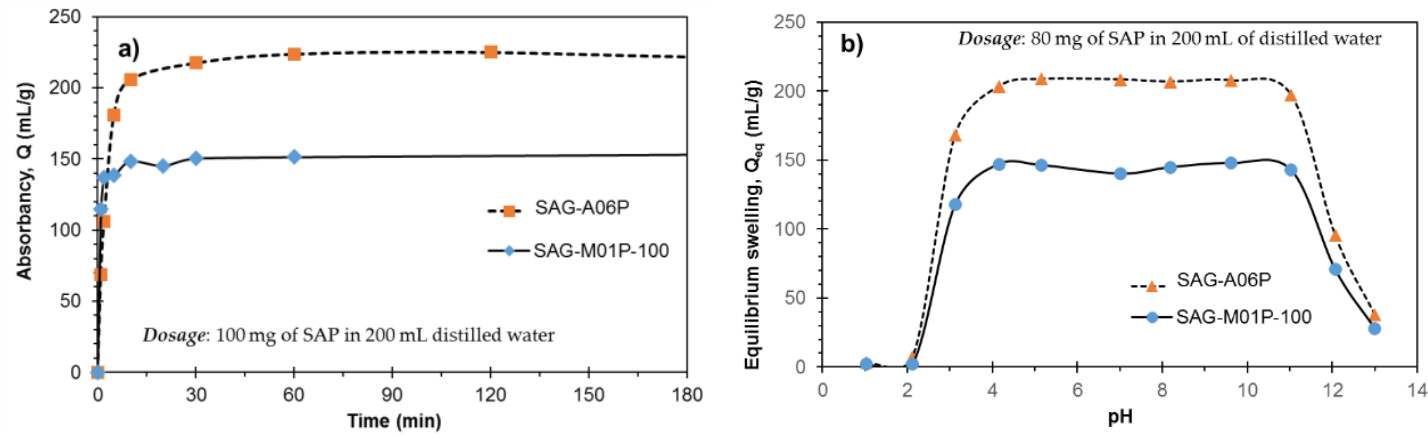

Figure 6. Deionized water absorbency of the two grades of SAP: (a) kinetic of SAP hydrogels formation and absorbency $Q,(\mathbf{b})$ equilibrium degree of swelling $\left(Q_{\text {eq }}\right)$ as a function of $\mathrm{pH}$.

Three series of tests are carried out: $(i)$ mine water (= tailings slurry supernatant water) absorbency tests using beakers (series \#1), (ii) mine tailings slurry dewatering tests using Pyrex dishes (series \#2), and (iii) mine tailings slurry dewatering tests using plastic bins (series \#3). Series \#1 tests are intended to further understand the absorption kinetics of the tailings slurry supernatant water. Series \#2 and \#3 tests are designed to understand the dewatering of tailings slurry by varying the volume tested.

\subsubsection{Series \#1: Mine Water Absorbency Tests Using Beakers}

These tests consisted of introducing a known mass of SAP into a beaker containing a certain amount of mine water (here, $100 \mathrm{~mL}$ for grade 1 SAP and $200 \mathrm{~mL}$ for grade $2 \mathrm{SAP}$ based on the results in Figure 6a) for a residence time of $24 \mathrm{~h}$ by direct addition mode (Figure 7 ). The SAP dosages ranged between 8 and $40 \mathrm{~kg} / \mathrm{m}^{3}$ of mine water for grade 1 SAP and between 8 and $20 \mathrm{~kg} / \mathrm{m}^{3}$ of mine water for grade 2 SAP.
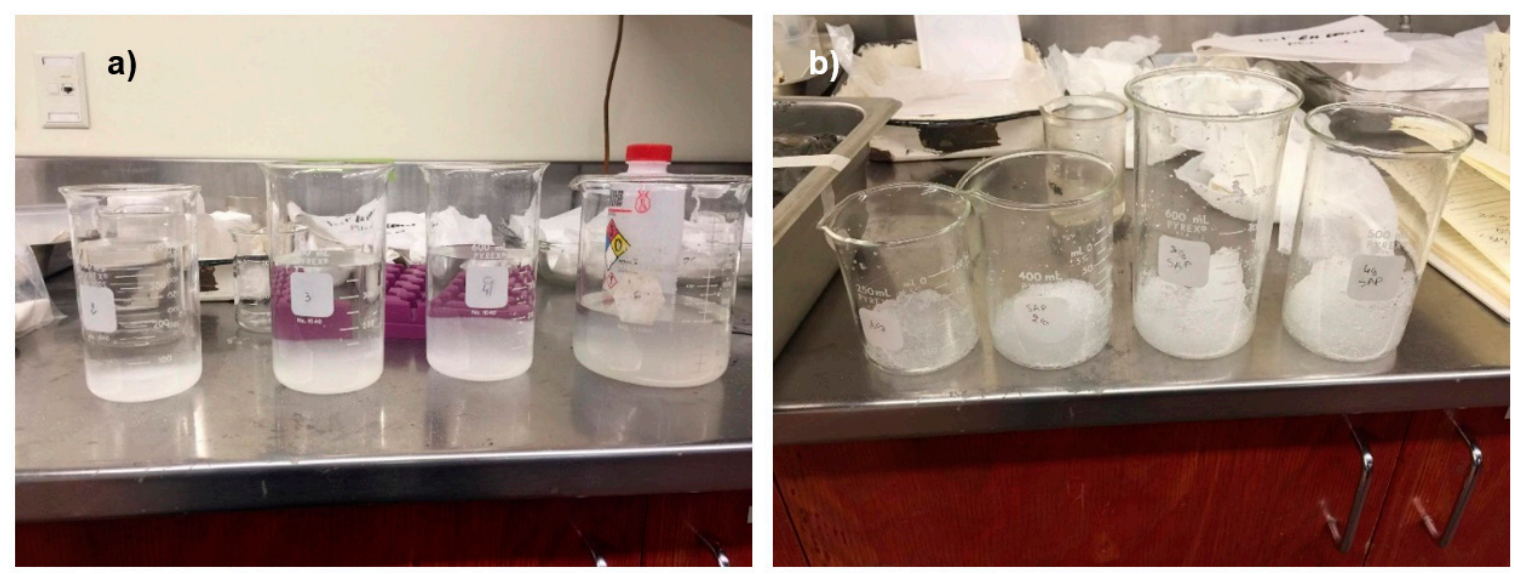

Figure 7. Series \#1: mine water absorption tests: (a) the beakers with water before the SAP addition, (b) after the SAP was added directly. 


\subsubsection{Series \#2: Mine Tailings Slurry Dewatering Tests Using Pyrex Dishes}

These tests consisted of soaking the SAP contained in geotextile bags (indirect addition mode) in order to densify the tailings slurry. For this purpose, a known mass of SAP is introduced into geotextile bags (see Figure 8a), which are then soaked into the tailings slurry (with an initial mass $M_{\text {Slury }}$ ) previously placed in Pyrex dishes (see Figure $8 b$ ). The Pyrex dishes were then covered with plastic foil to avoid any evaporation. These tailings slurries dewatering tests were performed for understanding the impact of the SAP dosages and residence time on their water absorbent capacity. Different SAP dosages (Table 3) were used with tailings slurry having a known initial solids mass concentration $C_{\mathrm{w} \% \_ \text {initial }}$. The $C_{\mathrm{w} \% \text { _initial }}$ was set arbitrarily at 50\% (gravimetric water content $w=100 \%$ ) for grade $1 \mathrm{SAP}$, and at $43 \%(w=133 \%)$ for grade $2 \mathrm{SAP}$. Three soaking times (or residence times) were tested: 24,48 , and $72 \mathrm{~h}$. After each residence time, the final gravimetric water content $w(\%)_{\text {final }}$ and the corresponding final solids content $\left(C_{\mathrm{w}_{-} \text {ffinal }_{1}}\right)$ of the resulting densified tailings were determined using one or the other of the following equations (according to the determined parameters):

$$
\begin{gathered}
C_{w \%_{\_} \text {final }}=C_{w \%_{\_} \text {initial }} \times \frac{M_{\text {slurry }}}{M_{\text {slurry }}-\left(M_{\text {swollen-SAP }}-M_{\text {dry-SAP }}\right)}, \\
C_{w \%_{-} \text {final }}=100 \times\left(1+\frac{w(\%)_{\text {final }}}{100}\right)^{-1},
\end{gathered}
$$

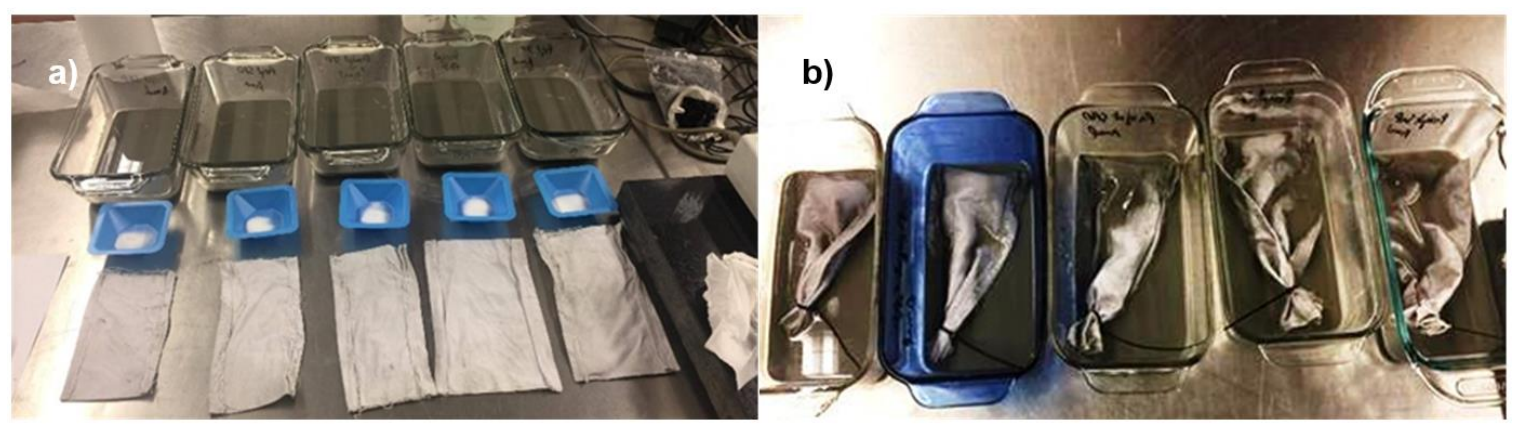

Figure 8. Series \#2: tailings slurry in Pyrex dishes: (a) before the SAP addition and SAPs in separate dishes next to the geotextile bags (indirect addition mode), (b) $24 \mathrm{~h}$ after the placement of geotextile bags containing the SAPs into the tailings slurry.

\begin{tabular}{|c|c|c|c|c|}
\hline \multirow{2}{*}{ Test\# } & \multicolumn{2}{|c|}{ Grade 1 SAP } & \multicolumn{2}{|c|}{ Grade 2 SAP } \\
\hline & $M_{\text {dry-SAP }}(\mathrm{g})$ & ${ }^{*} D_{\mathrm{vSAP}-\mathrm{s}}\left(\mathrm{kg} / \mathrm{m}^{3}\right)$ & $M_{\text {dry-SAP }}(\mathrm{g})$ & ${ }^{*} D_{\mathrm{vSAP}-\mathrm{s}}\left(\mathrm{kg} / \mathrm{m}^{3}\right)$ \\
\hline$\# 1$ & 0.8 & 5.8 & 0.8 & 5.5 \\
\hline$\# 2$ & 0.85 & 6.2 & 0.85 & 5.8 \\
\hline$\# 3$ & 0.9 & 6.6 & 0.9 & 6.2 \\
\hline$\# 4$ & 0.95 & 6.9 & 0.95 & 6.5 \\
\hline \#5 & 1 & 7.3 & 1 & 6.8 \\
\hline \#6 & 1.1 & 8.0 & 1.05 & 7.2 \\
\hline \#7 & 1.5 & 10.9 & 1.1 & 7.5 \\
\hline$\# 8$ & 1.6 & 11.7 & 1.15 & 7.9 \\
\hline$\# 9$ & 1.7 & 12.4 & 1.2 & 8.2 \\
\hline$\# 10$ & 1.8 & 13.1 & 1.25 & 8.6 \\
\hline \#11 & 1.9 & 13.8 & & \\
\hline
\end{tabular}

Table 3. Series \#2: SAP dosages for the tests using Pyrex dishes.

${ }^{*} M_{\text {slurry }}=200 \mathrm{~g}$; for grade 1 SAP: $C_{w \% \_ \text {initial }}=50 \%, \rho_{\text {slurry }}=1457.4 \mathrm{~kg} / \mathrm{m}^{3}$ and $V_{\text {slurry }}=0.137 \mathrm{~L} ;$ for grade 2 SAP: $C_{\text {W } \% \text { initial }}=43 \%, \rho_{\text {slurry }}=1369.4 \mathrm{~kg} / \mathrm{m}^{3}$ and $V_{\text {slurry }}=0.146 \mathrm{~L}$. 


\subsubsection{Series \#3: Mine Tailings Slurry Dewatering Tests Using Plastic Bins}

The tailings slurry dewatering tests using the plastic bins were carried out for evaluating the effect of the slurry initial solids mass concentration $\left(C_{\mathrm{w} \% \text { initial }}\right)$ on the SAP absorption capacity (Figure 9$)$. This was investigated by adding three SAP masses $(4,7$, and $9 \mathrm{~g}$ of SAP $/ 1 \mathrm{~kg}$ of slurry) to $30 \mathrm{~kg}$ of

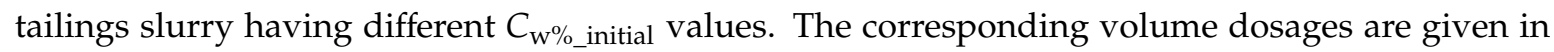
Table 4 . The initial solids mass concentration was varied from $7 \%$ to $74 \%$. After $72 \mathrm{~h}$ of residence time (or soaking time), the final gravimetric water content $w(\%)_{\text {final }}$ and the corresponding final solids mass concentration $\left(C_{\mathrm{w} \% \_ \text {final }}\right)$ of the densified tailings were determined.
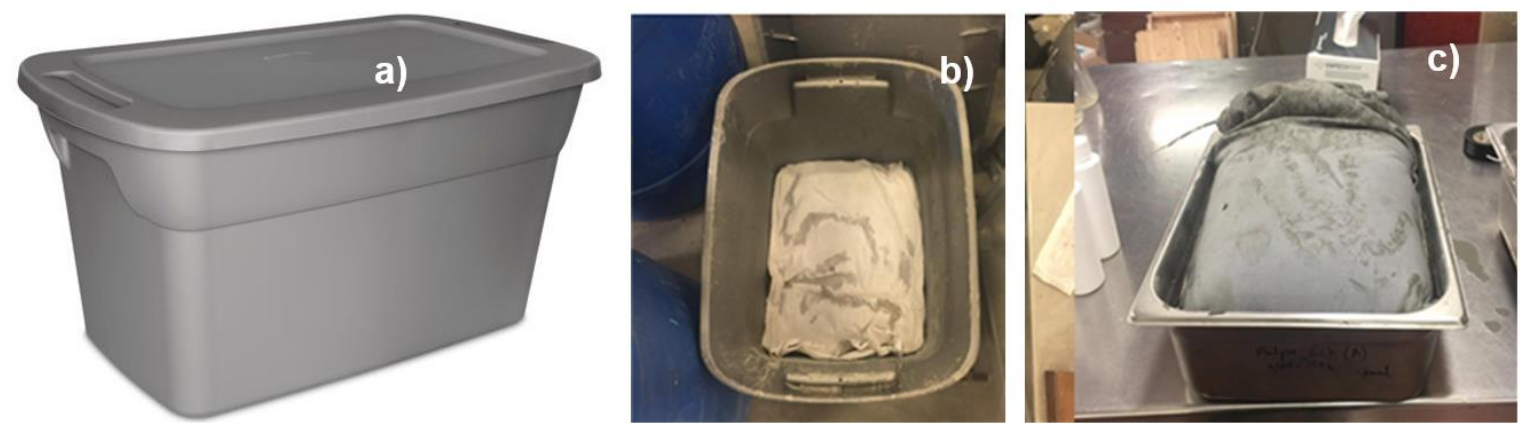

Figure 9. Series \#3: plastic bins dewatering tests: (a) the empty plastic bin, (b) almost dry tailings slurry obtained using geotextile bags with SAP (72 h residence time), (c) swollen SAP in a geotextile bag (after $72 \mathrm{~h})$.

Table 4. Series \#3: grade 1 SAP dosages for the tests using plastic bins.

\begin{tabular}{|c|c|c|c|c|}
\hline Test\# & $M_{\text {dry-SAP }}$ * & $\begin{array}{c}\rho_{\text {slurry }} \\
\left(\mathrm{kg} / \mathrm{m}^{3}\right)\end{array}$ & $\underset{\mathbf{( \% )}}{C_{\mathbf{w} \% \text { initial }}}$ & $\begin{array}{l}D_{\mathrm{vSAP}-\mathrm{s}} \\
\left(\mathrm{kg} / \mathrm{m}^{3}\right)\end{array}$ \\
\hline$\# 1$ & 120 & 1049 & 7 & 4.2 \\
\hline$\# 2$ & 120 & 1078 & 11 & 4.3 \\
\hline$\# 3$ & 120 & 1121 & 17 & 4.5 \\
\hline$\# 4$ & 120 & 1457 & 50 & 5.8 \\
\hline \#5 & 120 & 1717 & 66 & 6.9 \\
\hline \#6 & 120 & 1873 & 74 & 7.5 \\
\hline \#7 & 210 & 1252 & 32 & 8.8 \\
\hline$\# 8$ & 210 & 1326 & 39 & 9.3 \\
\hline$\# 9$ & 210 & 1426 & 47 & 10.0 \\
\hline$\# 10$ & 270 & 1153 & 21 & 10.4 \\
\hline$\# 11$ & 270 & 1325 & 39 & 11.9 \\
\hline$\# 12$ & 270 & 1434 & 48 & 12.9 \\
\hline
\end{tabular}

$* M_{\text {slurry }}=30 \mathrm{~kg}$; grade 1 SAP used; $120 \mathrm{~g}$ of SAP $=4 \mathrm{~g} / \mathrm{kg}$ of slurry; $210 \mathrm{~g}$ of SAP $=7 \mathrm{~g} / \mathrm{kg}$ of slurry; $270 \mathrm{~g}$ of SAP $=9$ $\mathrm{g} / \mathrm{kg}$ of slurry.

\section{Results}

\subsection{Equilibrium Degree of Swelling of SAP ( $\left.Q_{e q}\right)$ Using Mine Water (Series \#1 Tests)}

Figure 10 presents the equilibrium degree of swelling $\left(Q_{\mathrm{eq}}\right)$ of the SAP when placed in contact with mine water directly for $24 \mathrm{~h}$ residence time. For both SAPs, $Q_{\text {eq }}$ increases and reaches a maximum value for a SAP dosage between 10 and $15 \mathrm{~kg} / \mathrm{m}^{3}$. Beyond $15 \mathrm{~kg} / \mathrm{m}^{3}, Q_{\text {eq }}$ seems to decrease. It can be observed that the maximum $Q_{\text {eq }}$ using the grade 1 SAP (SAG-A06P) is $53 \mathrm{~mL} / \mathrm{g}$ and $43 \mathrm{~mL} / \mathrm{g}$ using the grade 2 SAP (SAG-M01P-100). These maximum $Q_{\text {eq }}$ values correspond to $24 \%$ and $28 \%$ of the absorbency in deionized water using grade 1 and grade 2 SAPs, respectively. If for deionized water the grade 2 SAP absorption capacity is $67 \%$ of that of grade 1 SAP, for the Mine A water the grade 2 SAP absorption capacity is $81 \%$ of that of the grade 1 SAP. 


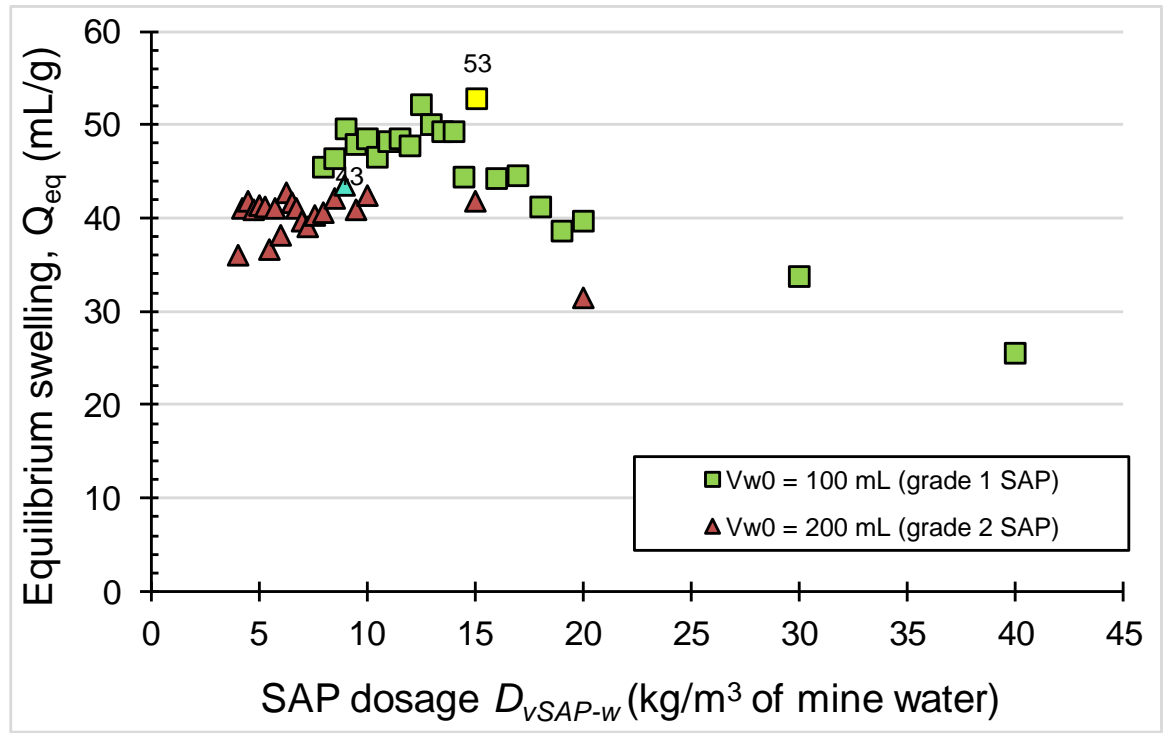

Figure 10. Mine A water absorbent capacity of SAP after $24 \mathrm{~h}$ residence time $\left(Q_{\text {eq }}\right)$ by using grade 1 SAP (SAG-A06P) and grade 2 SAP (SAG-M01P-100).

\subsection{Dewatering of Tailings Slurry Using SAP Geotextile Bags}

\subsubsection{Pyrex Dishes Tailings Dewatering Tests (Series \#2 Tests)}

Figure 11 presents the results of densifying a tailings slurry at $C_{\mathrm{w}_{-} \text {_initial }}$ at $50 \%$ using grade 1 SAP geotextile bags for different polymer dosages and residence times. Figure 11a presents the change in SAP equilibrium degree of swelling $\left(Q_{\mathrm{eq}}\right)$ and Figure $11 \mathrm{~b}$ presents the calculated $C_{\mathrm{w} \% \text { ffinal. }}$. It can be noted that for $D_{\text {vSAP-s }}$ in the range $5.8-8.0 \mathrm{~kg} / \mathrm{m}^{3}, Q_{\text {eq }}>40 \mathrm{~g} / \mathrm{g}$ while above this range of dosage $Q_{\text {eq }}<$ $40 \mathrm{~g} / \mathrm{g}$. The maximum $Q_{\mathrm{eq}}=53 \mathrm{~g} / \mathrm{g}$ without any obvious and clear trend (see Figure 11a). At the end of the tests, the SAP geotextile bags were very swollen (see Figure 9c). This is because the polymer particles swell due to the tailings slurry free pore water absorption. Indeed, due to higher osmotic pressure difference between the inside and outside of the SAP (mine water) the polymer particles absorbed the tailings pore water which is retained in the polymer chains as previously described by different authors $[18,24,25]$.
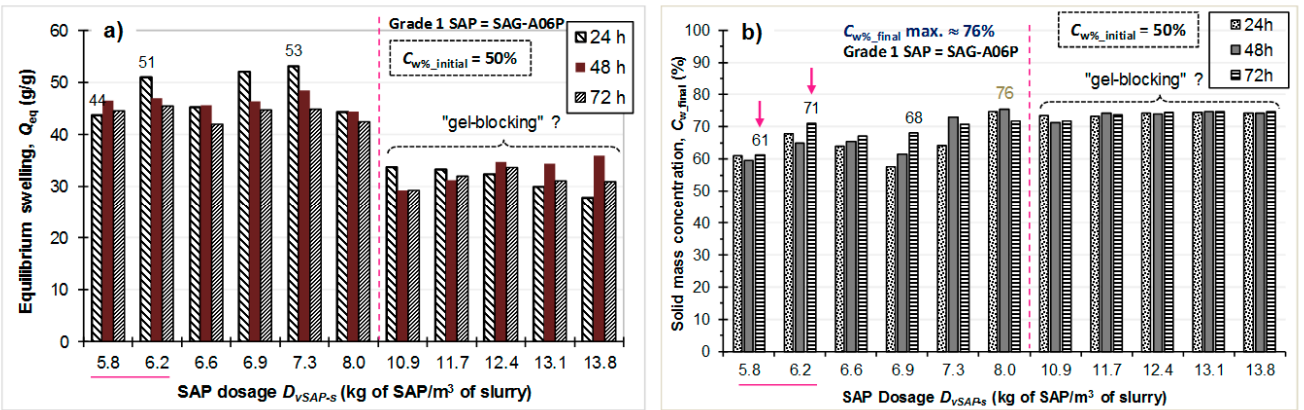

Figure 11. Tailings slurry at $C_{\mathrm{w} \% \text { _initial }}=50 \%$ dewatered at different dosages of grade $1 \mathrm{SAP}$ (SAG-A06P): (a) equilibrium swelling $Q_{\text {eq }}$ for three different residence times, (b) final solids concentration $C_{\mathrm{w} \% \text { _final }}$.

From Figure $11 \mathrm{~b}$ it can be observed that for $D_{\mathrm{vSAP}-\mathrm{s}}$ in the range $5.8-8.0 \mathrm{~kg} / \mathrm{m}^{3}, C_{\mathrm{w} \% \text { f final }}$ increases from $60 \%$ to $76 \%$, while above this range of dosage $C_{\mathrm{w} \% \text { final }}$ stabilizes around an average value of $74 \%$ and the effect of soaking time (or residence time) is limited, or non-existent, taking into account measurement errors. For $D_{\mathrm{vSAP}-\mathrm{s}} \geq 8.0 \mathrm{~kg} / \mathrm{m}^{3}$ of slurry, it was possible to densify the tailings slurry from $C_{\mathrm{w} \% \_ \text {initial }}=50 \%$ to $C_{\mathrm{w} \% \_ \text {final }}>70 \%$ by using SAPs recovered from unused defective diapers. 
Above $8 \mathrm{~kg} / \mathrm{m}^{3}$, the $Q_{\text {eq }}$ value becomes lower and its average value $(35 \mathrm{~mL} / \mathrm{g})$ is approximately $78 \%$ of that of the average value $(45 \mathrm{~mL} / \mathrm{g})$ obtained with dosages in the range $5.8-8 \mathrm{~kg} / \mathrm{m}^{3}$. This reduction in $Q_{\text {eq }}$ value can be related to the gel-blocking phenomenon and is discussed in Section 3.2.2 (see Figure 11).

Figure 12 presents the results of densifying a tailings slurry at $C_{\mathrm{w} \% \text { initial }}=43 \%$ using grade 2 (SAG-M01P-100) SAP geotextile bags for different polymer dosages and residence times. From Figure 12a it can be observed that for $Q_{\mathrm{eq}}>30 \mathrm{~g} / \mathrm{g}$, regardless of the residence time, the highest degree of swelling using $D_{\text {vSAP-s }}$ of $36 \mathrm{~g} / \mathrm{g}$ was achieved after $24 \mathrm{~h}$. From Figure $12 \mathrm{~b}$ it can be observed that $C_{\text {w\% }}$ final increases from $55 \%$ to $66 \%$ after $72 \mathrm{~h}$.
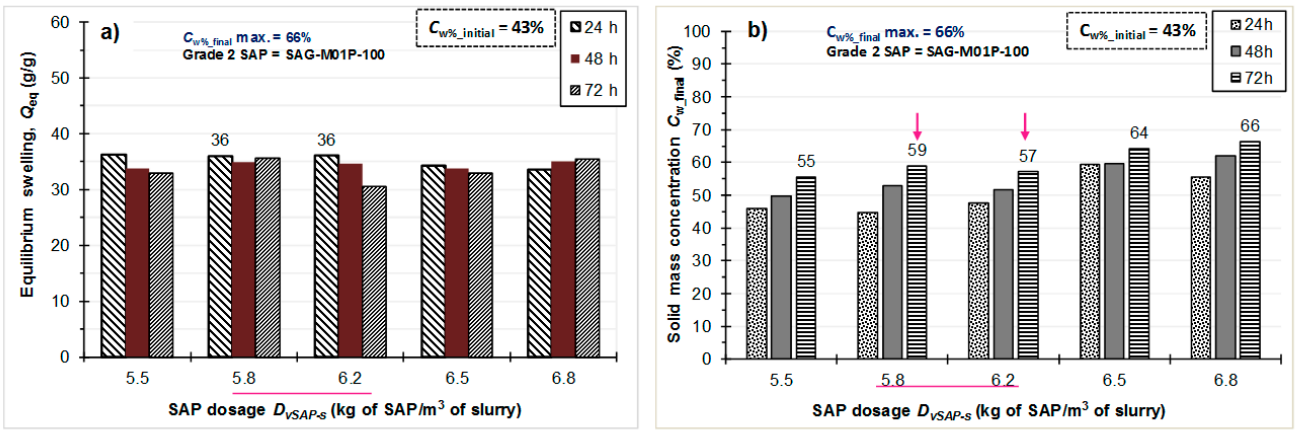

Figure 12. Tailings slurry at $C_{\mathrm{w} \% \text { initial }}=43 \%$ dewatered at different dosages of grade 2 SAP (SAG-M01P-100): (a) equilibrium swelling $Q_{\text {eq }}$ for three different residence times, (b) final solids concentration $C_{\mathrm{w}_{\%} \text { _final }}$.

To compare the performance of the two grades of polymer used (grades 1 and 2), only the two identical $D_{\mathrm{vSAP}-\mathrm{s}}$ values of 5.8 and $6.2 \mathrm{~kg} / \mathrm{m}^{3}$ are considered (values underlined in the abscissa axes). For these two dosages and comparing Figures 11a and 12a at the residence time of $24 \mathrm{~h}$ for example, it can be seen that $Q_{\text {eq }}$ is 44 and $51 \mathrm{~g} / \mathrm{g}$ when using the grade $1 \mathrm{SAP}$, while $Q_{\text {eq }}=36 \mathrm{~g} / \mathrm{g}$ when using the grade 2 SAP. In addition, by comparing Figures $11 \mathrm{~b}$ and $12 \mathrm{~b}$ at the residence time of $72 \mathrm{~h}$, it can be observed that $C_{\mathrm{w} \% \text { _final }}$ is $61 \%$ and $71 \%$ using grade $1 \mathrm{SAP}$, while $C_{\mathrm{w} \% \text { final }}$ is $59 \%$ and $57 \%$ using grade $2 \mathrm{SAP}$. From these results, it can be concluded that the equilibrium degree of swelling (or water absorbent capacity) of the grade 2 SAP is lower compared to the grade 1 SAP. This can be explained mainly by the difference in particles gradation (see Figure 6a). Indeed, grade 1 SAP is coarser than grade 2 SAP (see Table 2).

\subsubsection{Plastic Bins Tailings Dewatering Tests (Series \#3 Tests)}

Figure 13 presents all the results obtained following different tailings slurry dewatering tests according to SAP dosages presented in Table 4.

From Figure 13 it can be seen that $C_{\mathrm{w} \% \text { _initial }}$ influences the efficiency of the dewatering process of the tailing slurries using SAPs (grade 1 , coarser). Indeed, for low $C_{\mathrm{w} \% \text { initial }}$ tailings slurry $(7 \%$, $11 \%$, and $17 \%$ ), the use of SAP at dosages in the range $4.2-4.5 \mathrm{~kg} / \mathrm{m}^{3}$ allowed achieving $C_{\mathrm{w}_{\text {}} \text { _final }}$ of $21 \%, 29 \%$, and $31 \%$, respectively (corresponding to an increase of $201 \%, 155 \%$, and $80 \%$, respectively).

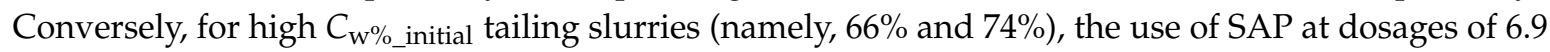
and $7.5 \mathrm{~kg} / \mathrm{m}^{3}$ allowed achieving $C_{\mathrm{w}_{-} \text {final }}$ of $78 \%$ for both (corresponding to an increase of $17 \%$ and $5 \%$,

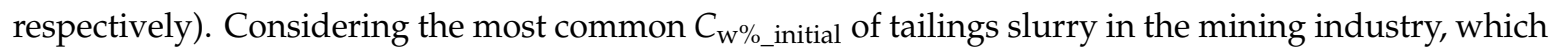
is about $50 \%$, a SAP dosage of $5.8 \mathrm{~kg} / \mathrm{m}^{3}$ yielded densified tailings at $C_{\mathrm{w} \% \text { _final }}$ of $67 \%$ (an increase of

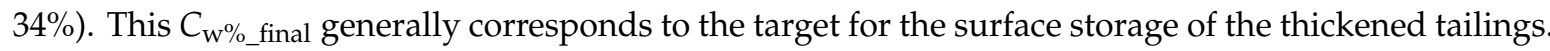

For $C_{\mathrm{w} \% \text { _initial }}$ tailings slurry of $32 \%, 39 \%$, and $47 \%$, the use of SAP at dosages in the range 8.8-10.0 $\mathrm{kg} / \mathrm{m}^{3}$ allowed achieving $C_{\mathrm{w} \% \text { final }}$ of $38 \%, 49 \%$, and $50 \%$, respectively (corresponding to an increase of $20 \%, 27 \%$, and $6 \%$, respectively). This low level of dewatering could be due to a possible gel-blocking phenomenon. Gel-blocking (see Figure 14) occurs when the wetted surface of an SAP particle swells 
and impedes flow of liquid into the interior of the SAP particle, and frequently occurs with high absorbency SAPs that also have low percolation rate or permeability [30,31]. In fact, it is believed that this phenomenon is inherent to the soaking method using the SAP in geotextile bags or to the direct addition mode in the case of a probable overdosing (see Figure 11a for $D_{\mathrm{vSAP}-\mathrm{s}}>8 \mathrm{~kg} / \mathrm{m}^{3}$ ). Indeed, after absorbing a certain amount of water, the polymers can form a gel on the surface of the geotextile bags that prevents water from penetrating deep. This formed "gel-screen" drastically reduces access of water to the rest of the polymers in the geotextile bags (Figure 14).

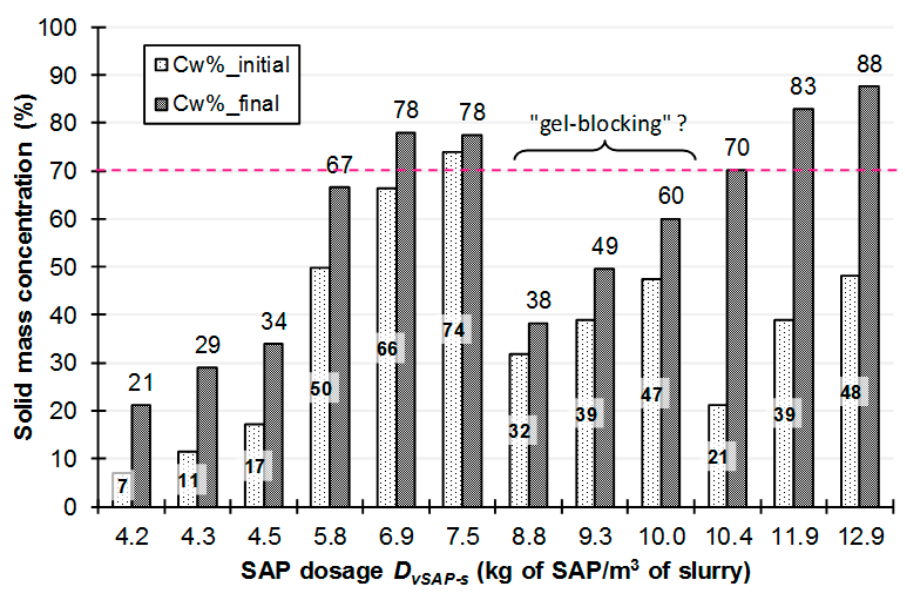

Figure 13. Results of tailings slurry dewatering using $D_{\mathrm{vSAP}-\mathrm{s}}$ in the range $4.2-12.9 \mathrm{~kg} / \mathrm{m}^{3}$ of grade 1 SAP and after $72 \mathrm{~h}$ residence time.

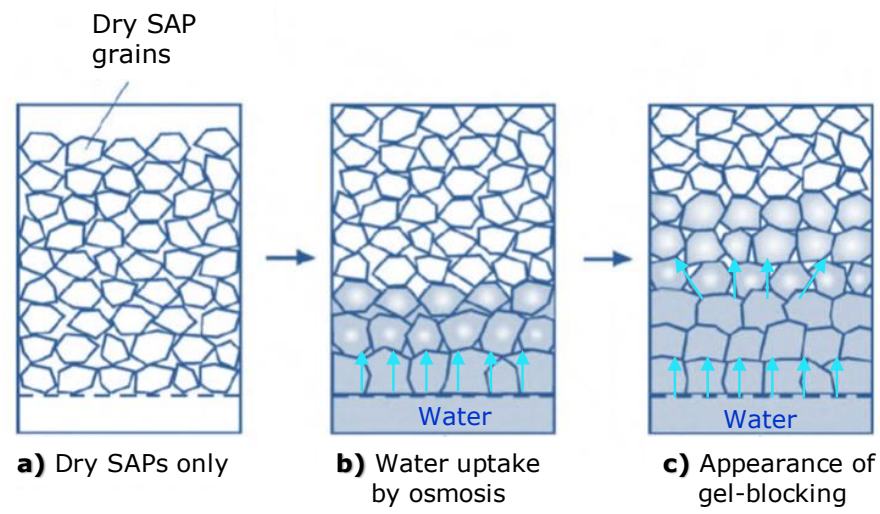

Figure 14. Schematic illustration of the mechanism of gel-blocking (modified from [30]).

For $C_{\mathrm{w} \% \text { _initial }}$ tailings slurry of $21 \%, 39 \%$, and $48 \%$, the use of SAP at dosages in the range 10.4-12.9 $\mathrm{kg} / \mathrm{m}^{3}$ allowed achieving $C_{\mathrm{w} \% \text { final }}$ of $70 \%, 83 \%$, and $88 \%$, respectively (corresponding to an increase of $233 \%, 113 \%$, and $82 \%$, respectively). It can be noted that gel-blocking did not occurred and the reason could simply be due to a better placement of the geotextile bags with the SAPs in the tailings slurry. The results show a very good performance of tailings slurry dewatering with SAP at $D_{\mathrm{vSAP}-\mathrm{s}}$ in the range $10.4-12.9 \mathrm{~kg} / \mathrm{m}^{3}$. Indeed, within this range of $D_{\mathrm{vSAP}-\mathrm{s}}$ it was possible to densify the tailing slurries to a final solids mass concentration $\geq 70 \%$.

The comparison of the tests performed using 9.3 and $10.0 \mathrm{~kg} / \mathrm{m}^{3}$ dosages $\left(C_{w_{\%}}\right.$ _initial of $39 \%$ and $47 \%)$ to those performed using 11.9 and $12.9 \mathrm{~kg} / \mathrm{m}^{3}\left(C_{\mathrm{w} \% \text { initial }}\right.$ of $39 \%$ and $\left.48 \%\right)$ supports the hypothesis of polymers gel-blocking phenomenon (Figures 11a and 13). Despite the high dewatering performance of the SAPs, the gel-blocking phenomenon is still present and represents a challenge when using geotextile bags method. Since the dosages in the range $10.4-12.9 \mathrm{~kg} / \mathrm{m}^{3}$ are considered very high, the obtained $C_{\mathrm{w} \% \text { final }}$ in the range $70-88 \%$ are expected to be even higher. 


\section{Discussion}

\subsection{Evolution of the Percentage of Absorbed Mine Water}

From Figure 15 it can be observed that the apparent maximum rate of absorbed water $W_{\mathrm{SAP}}(\%)$ was $100 \%$ when using grade 1 SAP at dosages $\geq 30 \mathrm{~kg} / \mathrm{m}^{3}$ and $60 \%$ when using grade 2 SAP at dosages $\geq 20 \mathrm{~kg} / \mathrm{m}^{3}$. It should be noted that $W_{\mathrm{SAP}}=60 \%$ would be achieved with a dosage in the range 10-15 $\mathrm{kg} / \mathrm{m}^{3}$ of grade 1 SAP (see Figure 15). The rate of absorbed mine water of grade 2 SAP is lower in comparison to the grade 1 SAP. These preliminary results confirmed that the use of SAPs that are reclaimed from industrial reject of baby diapers results in very good absorbency of mine water.

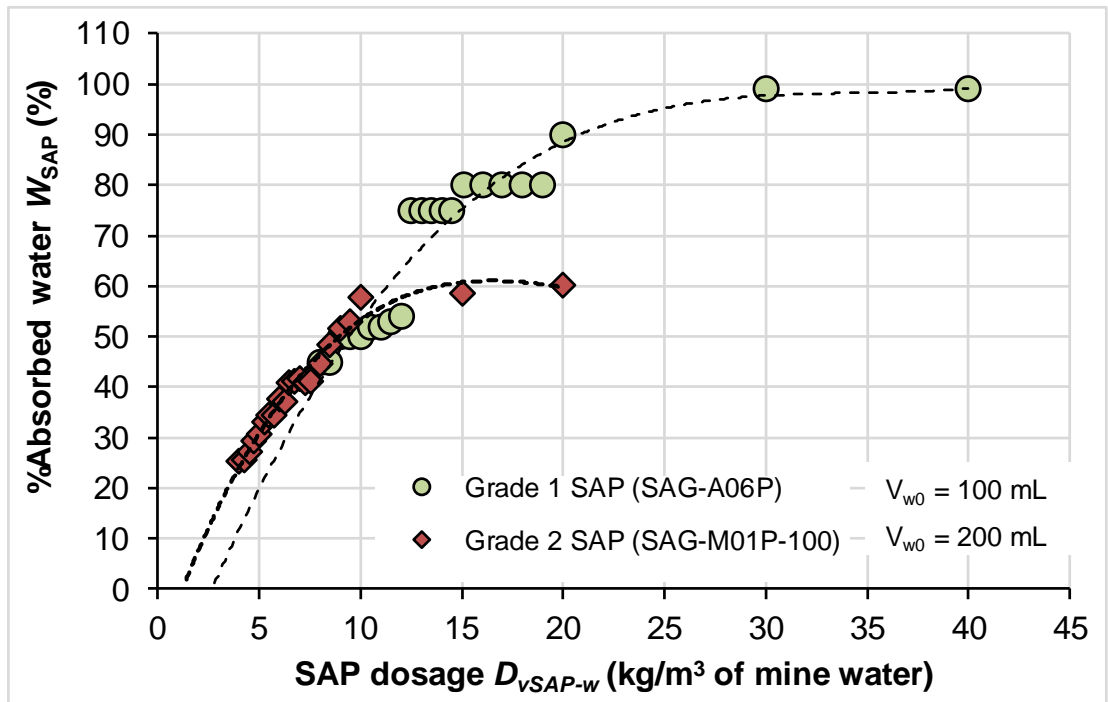

Figure 15. Mine A water absorption capacity of coarser SAP (grade $1=$ SAG-A06P) and the finer SAP (grade 2 = SAG-M01P-100).

\subsection{Effect of Residence Time on Tailings Dewatering}

Figure 16 presents the variation in tailings slurry final solids mass concentration after dewatering at three different residence time $(24,48$, and $72 \mathrm{~h})$. It can be observed that the residence time does not have much influence on the effectiveness of the dewatering of tailings slurry, using SAPs recovered from unused defective diapers. Indeed, for the same SAP dosage of $6.6 \mathrm{~kg} / \mathrm{m}^{3}$, the final solids percentage $C_{\mathrm{w} \% \text { final }}$ obtained with grade $1 \mathrm{SAP}$ is $64 \%, 65 \%$, and $67 \%$ after 24,48 , and $72 \mathrm{~h}$, respectively. In addition, by using grade 2 polymers, the final $C_{\mathrm{w} \% \text { final }}$ values are $59 \%, 60 \%$, and $64 \%$ after 24,48 , and $72 \mathrm{~h}$, respectively.
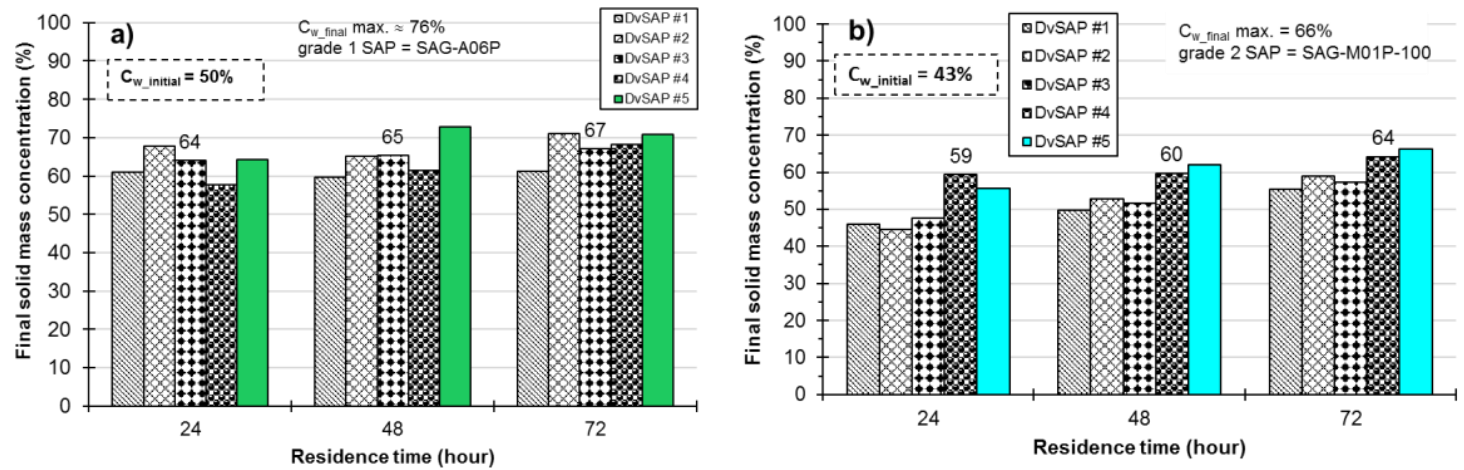

Figure 16. $C_{\mathrm{W} \% \text { final }}$ of densified tailings slurry as a function of residence time for five dosages (\#1 to \#5 in Table 3) using: (a) grade 1 SAP (SAG-A06P), (b) grade 2 SAP (SAG-M01P-100). 
Figure 17 shows that for the same SAP dosage of $6.6 \mathrm{~kg} / \mathrm{m}^{3}$, the increase of $C_{\mathrm{w} \text { _final }}$ using grade 1 polymers is $28 \%, 31 \%$, and $34 \%$ (after 24,48 , and $72 \mathrm{~h}$, respectively), and using grade 2 polymers, it is $38 \%, 39 \%$, and $49 \%$ (after 24,48 and $72 \mathrm{~h}$, respectively). It can be emphasized that because of the difference in $C_{\mathrm{w} \% \text { initial }}(50 \%$ and $43 \%$ ), the grade 2 polymers seem to have absorbed more water than the grade 1 polymers that are likely to be more efficient.
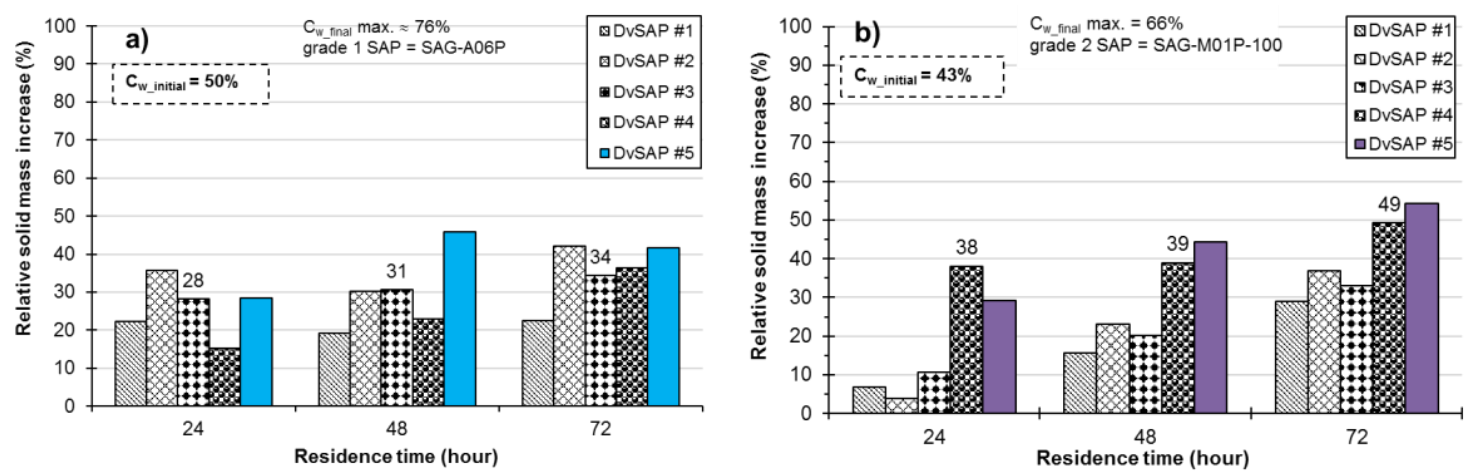

Figure 17. Tailings slurry relative solids mass concentration increase regarding the residence time and five SAP dosages: (a) grade 1 SAP (SAG-A06P), (b) grade 2 SAP (SAG-M01P-100).

\subsection{Empirical Relationship for Tailings Dewatering Using SAPS}

Figure 18 shows correlation curves between $C_{\mathrm{w} \% \text { initial }}$ and $C_{\mathrm{w} \% \text { final }}$ for all the tests performed using plastic bins. As a first approximation, a power law exists between the two states (initial and final) depending on the dosage range.
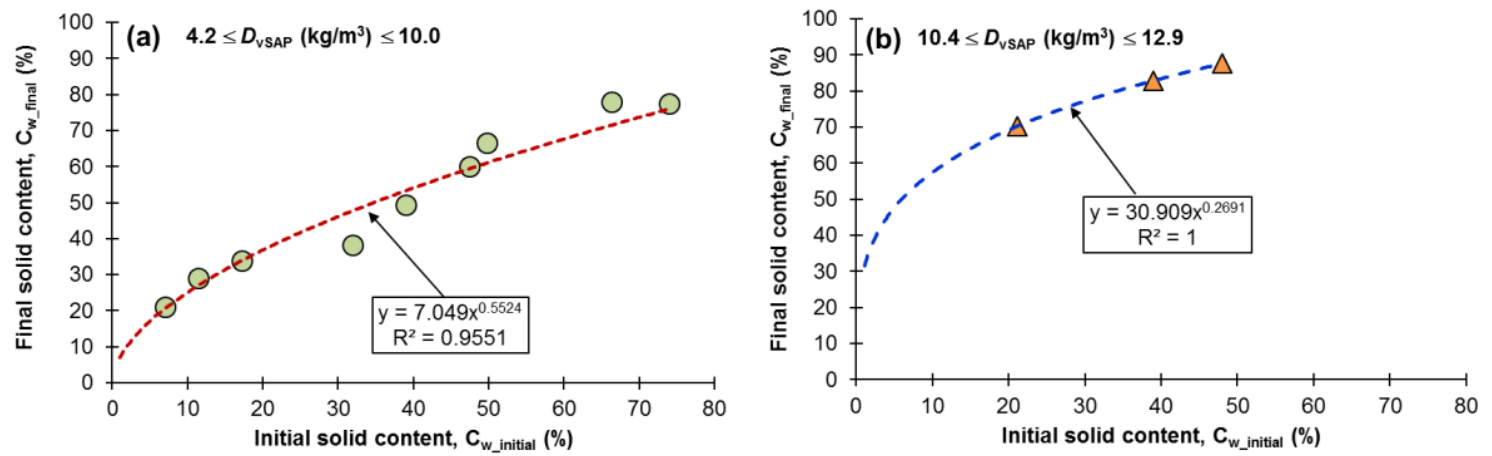

Figure 18. Power law empirical correlations between $C_{\mathrm{w} \% \text { _initial }}$ and $C_{\mathrm{w} \% \text { _final }}$ using grade $1 \mathrm{SAP}$ (SAG-A06P): (a) for $D_{\mathrm{vSAP}-\mathrm{s}}$ in the range $4.2-10 \mathrm{~kg}$ of SAP $/ \mathrm{m}^{3}$ of slurry, (b) for $D_{\mathrm{VSAP}-\mathrm{s}}$ in the range $10.4-12.9 \mathrm{~kg}$ of $\mathrm{SAP} / \mathrm{m}^{3}$ of slurry.

This power law relationship is given as follows:

$$
C_{w \% \_ \text {final }}=a \times\left(C_{w \% \text { initial }}\right)^{b},
$$

where $a=7.049, b=0.5524$ and $r=0.98$ for $D_{\mathrm{vSAP}-\mathrm{s}}$ in the range $4.2-10 \mathrm{~kg}$ of SAP $/ \mathrm{m}^{3}$ of slurry and $C_{\mathrm{W} \% \text { initial }}$ in the range $7-70 \% ; a=30.909, b=0.2691$ and $r=1.00$ for $D_{\text {vSAP-s }}$ in the range $10.4-12.9 \mathrm{~kg}$ of $\mathrm{SAP} / \mathrm{m}^{3}$ of slurry and $C_{\mathrm{w} \% \text { initial }}$ in the range $10-60 \%$.

\subsection{Regeneration of the SAPs for Their Multiple Reuse and Preliminary Economic Analysis}

One of the advantages of superabsorbent polymers is the ability to desorb the absorbed water to be returned to the water reuse loop at the mine, while the SAPs could be reused in turn several times (case of indirect addition mode). Indeed, some authors have proved that SAPs can be reused at least five times without losing their water absorbent capacity [24,25]. The regeneration capacity of SAPs 
(number of water absorption/desorption cycles) shall be evaluated for each type of SAP and for each SAP dosage. The water desorption from the SAPs can be carried out according to different techniques: by heat treatment (drying at $\mathrm{T} \leq 180^{\circ} \mathrm{C}$ ), by $\mathrm{pH}$ control (very acidic or basic), by electrolysis, or simply by the use of a saline solution (eg $1 \mathrm{~mol} / \mathrm{L}$ ). However, the economic feasibility analysis of the water desorption method should be done because an industrial desorption and water recovery unit will have to be built in a suitable location. At this stage of the study, there are still many steps before considering industrial application as economic viability has not yet been proven.

One disadvantage of the technique of dehumidification of tailings slurry using SAPs is the fact that it is a physico-chemical process (and not a mechanical one, as in conventional cases) which can therefore be affected by various factors such as the degree of crosslinking of SAPs, the presence of dior tri-valent dissolved cations, the presence of salts, very acidic or basic $\mathrm{pHs}$ and temperature.

To determine the economic feasibility of tailings slurry dehumidification using SAPs, it is essential to be able to compare costs with conventional techniques (thickeners and filtering systems). Table 5 contains comparative cost data for the different existing tailings dewatering technologies. This table also contains the estimated values - by interpolation of the test results — of the SAP dosages allowing obtaining the different equivalent consistencies.

Table 5. Typical relative operating cost (US $\$ / t)$ of tailings storage for different tailings dewatering technologies [32] and corresponding estimated equivalent SAP dosages.

\begin{tabular}{ccccc}
\hline $\begin{array}{c}\text { Tailings } \\
\text { Consistency }\end{array}$ & $\begin{array}{c}\text { Initial Solids } \\
\text { Content (\%) }\end{array}$ & $\begin{array}{c}\text { Typical Solids } \\
\text { Content at } \\
\text { Deposition (\%) }\end{array}$ & $\begin{array}{c}\text { Thickeners \& } \\
\text { Filtration Systems } \\
\text { Costs (US \$/t Slurry) }\end{array}$ & $\begin{array}{c}\text { SAP Dosage (kg/t } \\
\text { Slurry) * }\end{array}$ \\
\hline Slurry & 25 & 45 & 0.15 & 11.65 \\
Thickened & 25 & 65 & 0.23 & 17.01 \\
High-density & 25 & 70 & 0.38 & 18.83 \\
Paste & 25 & 78 & 1.13 & 28.97 \\
Filter cake & 25 & 85 & 3.76 & 35.15 \\
\hline
\end{tabular}

Mine A, an open-pit gold mine, generates 53,614.00 t/day of dry tailings. If the slurry initial solids content is $25 \%$, this corresponds to a mass of $214,456.00 \mathrm{t} /$ day of tailings slurry to be stored on the surface. On Alibaba trade website, it can be seen that the price of SAPs of the sodium polyacrylate type varies between US $\$ 1000$ and 2800/t (or US $\$ 1.00$ and 2.80/kg). Table 6 contains calculations of the quantities of polymers needed per day and their associated costs (in US \$ per tonne of slurry and per day). As can be seen, the gross costs are exorbitant because they are between 10 and 77 times higher than those from thickeners and filtration systems (see Table 5). These ratios become between 2 and 15 when the SAPs are used at least five times (absorption/desorption cycles).

Table 6. Dewatering cost of Mine A tailings slurries for different equivalent tailings consistencies using superabsorbent polymers (price of SAP considered: US $\$ 1000.00 / t$ ).

\begin{tabular}{ccccc}
\hline $\begin{array}{c}\text { Equivalent } \\
\text { Consistency }\end{array}$ & $\begin{array}{c}\text { Mass of SAP } \\
\text { Needed (t/Day) }\end{array}$ & $\begin{array}{c}\text { Cost of SAP } \\
\text { (US \$/t Slurry) }\end{array}$ & $\begin{array}{c}\text { Total Cost of SAP } \\
\text { for 1 Use (US } \\
\text { \$/Day) }\end{array}$ & $\begin{array}{c}\text { Total Cost of SAP } \\
\text { for 5 Uses (US } \\
\text { \$/Day) }\end{array}$ \\
\hline Slurry & 2498 & 11.65 & 29,107 & 5821 \\
Thickened & 3648 & 17.01 & 62,051 & 12,410 \\
High-density & 4038 & 18.83 & 76,039 & 15,208 \\
Paste & 6213 & 28.97 & 179,985 & 35,997 \\
Filter cake & 8347 & 38.92 & 324,851 & 64,970 \\
\hline
\end{tabular}

For the case of Mine A and with a minimum SAP market price of US $\$ 1000 / t$, it will cost between US $\$ 29,000$ and US $\$ 325,000 /$ day with a single use of SAPs, while it will cost between US $\$ 6000$ and US $\$ 65,000 /$ day for five cycles of use. 
To obtain a ratio of 1 (i.e., equivalent costs between conventional technologies and that of superabsorbent polymers), the price of one tonne of SAPs should vary between US $\$ 65 / t$ (for slurry at $50 \%$ solids content) and US $\$ 485 / t$ (for filter cake at $85 \%$ solids content) by assuming five cycles of use. Thus, the average acceptable price would therefore be in the order of US $\$ 180$ per tonne of SAPs. Figure 19 compares the processing and transport costs of tailings to the ponds for conventional technologies and that using SAPs with an average price of US $\$ 180 / t$. From this figure, it can be seen that at an average price of US $\$ 180 / t$ of SAPs, it would be cheaper (compared to conventional technologies) to deposit the tailings in the state/consistency of paste or cake. From there the real question is: would it be possible to get SAPs with the same water absorbent capacity at this price? The answer can only be given by polymer manufacturers.

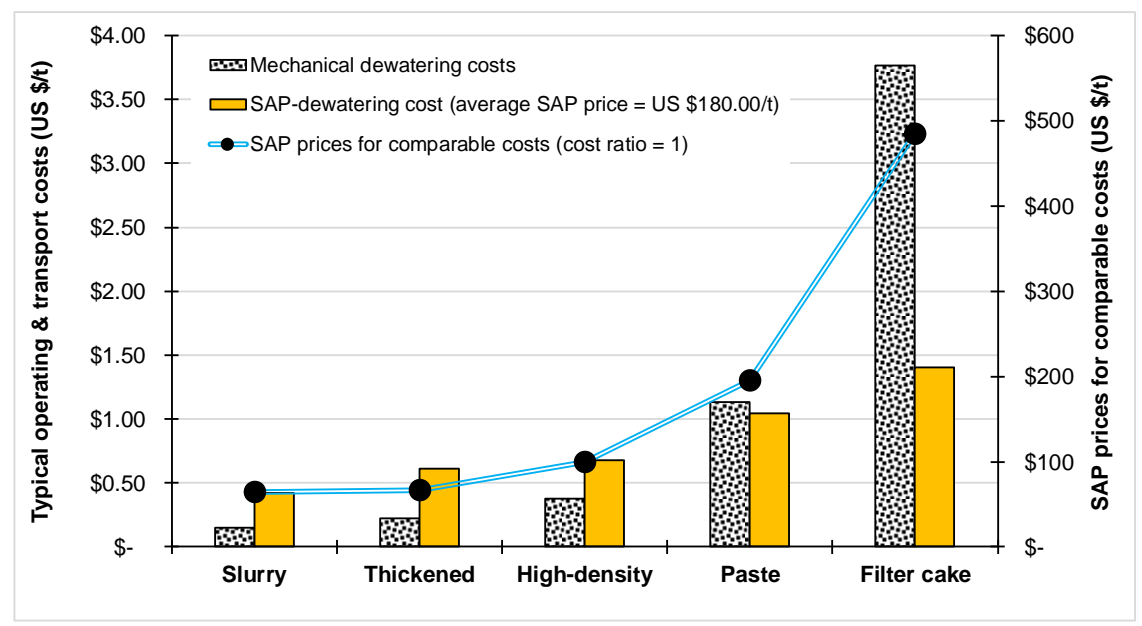

Figure 19. Comparison of the typical operating cost of tailings storage for conventional and SAPs tailings dewatering technologies (the average price of SAPS $=$ US $\$ 180 / t$ and 5 cycles of use).

\section{Conclusions}

The results from this preliminary study show that the use of SAPs reclaimed from unused (virgin) industrial reject of baby diapers should be a promising alternative for tailings slurry dewatering (or densification), owing to their relatively high capacity of water absorption, for surface storage in tailings storage facilities (TSF). The following concluding remarks can be made:

- The target final solids content $C_{\mathrm{w} \% \text { final }}$ of $68 \%$ was achieved for the Mine A tailings slurry;

- The coarser super absorbent polymers (SAPs) exhibit a higher absorbency (or equilibrium degree of swelling, $Q_{\mathrm{eq}}$ ) than the finer super absorbent polymers;

- The contact or residence time of the super absorbent polymers does not have a major impact on the amount of water absorbent capacity;

- Only the SAP dosages $\geq 10 \mathrm{~kg} / \mathrm{m}^{3}$ would make it possible to achieve the consistency of thickened tailings with a final solids mass concentration greater than $70 \%$;

- The occurrence of the gel-blocking phenomenon, which is reducing the water absorbent capacity of the super absorbent polymers in geotextile bags, has also been highlighted;

- Preliminary economic analysis has shown that, given the realities of the current SAP market, the costs of dewatering of tailings slurries would be very exorbitant for large-scale application;

- According to the results of this preliminary study, the acceptable price of SAPs would be only $18 \%$ of the current minimum market price of US $\$ 1000 / t$ (i.e., a price reduction of almost $82 \%$ ).

Author Contributions: Conceptualization, T.B. and A.S.; methodology, A.S., K.E.M. and T.B.; formal analysis, A.S., K.E.M., T.B., A.M. and M.M.; investigation, A.S., K.E.M. and T.B.; resources, T.B.; writing-original draft preparation, A.S. and T.B.; writing-review and editing, A.S., K.E.M., T.B., A.M., M.M.; visualization, K.E.M., A.M. and M.M.; supervision, T.B.; project administration, T.B.; funding acquisition, T.B., M.M. and A.M. 
Funding: This research was funded by FRQNT partnership program on Sustainable Development in the Mining Sector, grant number 2017-MI-202211 and the NSERC partnership Engage Grant, with the number EGP488714-15.

Acknowledgments: The authors would like to thank the governments of Quebec and Canada for their financial support through the Fonds de recherche du Québec, Nature et technologies (FRQNT) and NSERC Engage Grants program, respectively. The authors would also like to acknowledge the MCM for their partnership and financial support. They thank their partner Recyc PHP Inc. who provided them with the SAPs reclaimed from industrial reject of baby diapers.

Conflicts of Interest: The authors declare no conflict of interest. The funders had no role in the design of the study; in the collection, analyses, or interpretation of data; in the writing of the manuscript, or in the decision to publish the results.

\section{References}

1. Aubertin, M.; Bussière, B.; Bernier, L. Environnement et Gestion des Résidus Miniers [CD-ROM]; Les Presses Internationales Polytechniques: Montreal, QC, Canada, 2002.

2. Santamarina, J.C.; Torres-Cruz, L.A.; Bachus, R.C. Why coal ash and tailings dam disasters occur: Knowledge gaps and management shortcomings contribute to catastrophic dam failures. Sci. Mag. 2019, 364, 526-528. Available online: https://worldminetailingsfailures.org/ (accessed on 18 October 2019).

3. Bowker, L.N.; Chambers, D.M. In the dark shadow of The supercycle: Tailings failure risk \& public liability reach all time highs. Environments 2017, 4, 75. [CrossRef]

4. Bowker, L.N.; Chambers, D.M. Root Causes of Tailings Management Failures: The Severity of Consequence of Failures Attributed to Overtopping; Colorado State University: Fort Collins, CO, USA, 2016; pp. 1915-2015.

5. Bowker, L.N.; Chambers, D.M. The Risk, Public Liability and Economics of Tailings Storage Facility Failures; U.S. Department of Agriculture. Tonto National Forest: Payson, AZ, USA, 2015; 56p. Available online: https://www.resolutionmineeis.us/documents/bowker-chambers-2015 (accessed on 18 October 2019).

6. Azam, S.; Li, Q. Tailings dam failures: A review of the last one hundred years. Geotech. News 2010, $28,50-53$.

7. Davies, M.P. Tailings impoundment failures: Are geotechnical engineers listening. Geotech. News 2002, 20, 31-36.

8. International Commission on Large Dams (ICOLD), United Nations Environment Programme (UNEP). Tailings dams risk of dangerous occurrences-Lessons learnt from practical experiences. Bulletin 2001, 121, $1-144$.

9. Robinsky, E.I. Thickened discharge-New approach to tailings disposal. CIM Bull. 1975, 68, 47-53.

10. Landriault, D.A.; Verburg, R.; Cincilla, W.; Welch, D. Paste Technology for Underground Backfill and Surface Tailings Disposal Applications; Short Course Notes; Canadian Institute of Mining and Metallurgy, Technical Workshop: Vancouver, BC, Canada, 1997; 120p.

11. Jewell, R.J.; Fourie, A.B.; Lord, E.R. Paste and Thickened Tailings-A Guide; The Australian Center for Geomechanics: Nedlands, Australia, 2006; 173p.

12. Crowder, J.J. Deposition, Consolidation, and Strength of a Non-Plastic Tailings Paste for Surface Disposal. Ph.D. Thesis, University of Toronto, Toronto, ON, Canada, 2004; 162p.

13. Belem, T.; Benzaazoua, M. Design and application of underground mine paste backfill technology. Geotech. Geol. Eng. 2008, 26, 147-174. [CrossRef]

14. Benzaazoua, M.; Fall, M.; Belem, T. A contribution to understanding the hardening process of cemented pastefill. Miner. Eng. 2004, 17, 141-152. [CrossRef]

15. Kesimal, A.; Yilmaz, E.; Ercikdi, B. Evaluation of paste backfill mixtures consisting of sulphide-rich mill tailings and varying cement contents. Cem. Concr. Res. 2004, 34, 1817-1822. [CrossRef]

16. Lapierre, J. Étude Expérimentale du Comportement en Cisaillement de Résidus Miniers épaissis. Master's Thesis, Université de Sherbrooke, Sherbrooke, QC, Canada, 2014; 29p.

17. Wang, C.; Harbottle, D.; Liu, Q.; Xu, Z. Current state of fine mineral tailings treatment: A critical review on theory and practice. Miner. Eng. 2014, 58, 113-131. [CrossRef]

18. Zohuriaan-Mehr, M.J.; Kabiri, K. Superabsorbent polymer materials: A review. Iran. Polym. J. 2008, 17, 451477.

19. Ma, S.; Liu, M.; Chen, Z. Preparation and properties of a salt-resistant superabsorbent polymer. J. Appl. Polym. Sci. 2004, 93, 2532-2541. [CrossRef] 
20. Staples, T.L.; Chatterjee, P.K. Chapter VIII-Synthetic superabsorbents. Absorbent Technol. 2002, 13, $283-318$. [CrossRef]

21. Hassan, C.M.; Peppas, N.A. Structure and applications of Poly (Vinyl Alcohol) hydrogels produced by conventional crosslinking or by freezing/thawing methods. Adv. Polym. Sci. 2000, 153, 37-65.

22. Peer, F.; Venter, T. Dewatering of coal fines using a super absorbent polymer. J. South. Afr. Inst. Min. Metall. 2003, 103, 403-409.

23. Wang, X.; Feng, X.; Xu, Z.; Masliyah, J.H. Polymer aids for settling and filtration of oil sands tailings. Can. J. Chem. Eng. 2010, 88, 403-410. [CrossRef]

24. Farkich, A. SAP Based Rapid Dewatering of Oil Sands Mature Fine Tailings. Ph.D. Thesis, Université d'Ottawa/University of Ottawa, Ottawa, ON, Canada, 2013.

25. Farkish, A.; Fall, M. Rapid dewatering of oil sand mature fine tailings using super absorbent polymer (SAP). Miner. Eng. 2013, 50, 38-47. [CrossRef]

26. Ismi, I.; Elaidi, H.; Rifi, E.H.; Lebkiri, A.; Skalli, A. Comportement de polyacrylate de sodium au contact des solutions aqueuses en absence et en présence d'ions métalliques $\left(\mathrm{Ag}^{+}, \mathrm{Cu}^{2+}, \mathrm{Cr}^{3+}\right)$. J. Mater. Environ. Sci. 2015, 6, 1060-1067.

27. Bahaj, H.; Benaddi, R.; Bakass, M.; Bayane, C.; Bellat, J.P. Comportement du gonflement d'un polymère superabsorbant vis-à-vis de l'eau dans un sol sableux. In JEEP-Journées d'Étude des Équilibres entre Phases ( $p$. 00018); EDP Sciences: Annecy, France, 2009.

28. El'yashevich, G.K.; Bel'nikevich, N.G.; Vesnebolotskaya, S.A. Swelling-Contraction of Sodium Polyacrylate Hydrogels in Media with Different pH Values. Polym. Sci. Ser. A 2009, 51, 550-553. [CrossRef]

29. Sahi, A.; Belem, T.; Maqsoud, A.; Mbonimpa, M. Preliminary assessment of tailings pulp thickening using super absorbent polymers. In Proceedings of the 70th Canadian Geotechnical Conference GeoOttawa 2017, Ottawa, ON, Canada, 1-4 October 2017. 8p.

30. Wack, H.; Ulbricht, M. Gel blocking effects during the swelling of polymeric hydrogels. Ind. Eng. Chem. Res. 2007, 46, 359. [CrossRef]

31. Kuruwita-Mudiyanselage, T.D. Smart Polymer Materials. Ph.D. Thesis, Bowling Green State University, Graduate College, Bowling Green, OH, USA, 2008; 129p.

32. Klohn Crippen Berger (KCB). Report 2.50.1, Study of Tailings Management Technologies; Prepared for the Mine Environment Neutral Drainage (MEND) Project; NRCan: Ottawa, ON, Canada, 2017; 164p. 